\title{
Dynamic Tax Competition, Home Bias and the gain from Non-preferential Taxation Regimes: A case for unilateral commitment
}

Kaushal Kishore ( $\sim$ kishoreminx@gmail.com )

Indian Institute of Science Education and Research Bhopal

\section{Research Article}

Keywords: Dynamic tax competition, Non-preferential regime, Preferential regime, Home Bias

Posted Date: November 5th, 2021

DOI: https://doi.org/10.21203/rs.3.rs-1052559/v1

License: (c) (i) This work is licensed under a Creative Commons Attribution 4.0 International License.

Read Full License 
Dynamic Tax Competition, Home Bias and the gain from Non-preferential Taxation Regimes: A case for unilateral commitment

\author{
Kaushal Kishore ${ }^{1}$ \\ Assistant Professor \\ Department of Economic Sciences \\ Indian Institute of Science Education and Research (IISER) Bhopal \\ Bhopal Bypass Road, Bhauri, Bhopal 462066 Madhya Pradesh, India
}

December 11, 2020

\begin{abstract}
A country has an incentive to unilaterally commit to a non-preferential taxation regime even though the competitor adopts a preferential taxation regime. We show that a mixed taxation regime arises in a dynamic two-period model of tax competition between two symmetric countries where an investor has home-bias for the country where he/she invests in the initial period. A scenario where competing countries jointly adopt non-preferential taxation regimes is also a subgame-perfect equilibrium. The tax revenue of the country which adopts a preferential taxation regime in a mixed taxation regime is equal to the tax revenue a country receives when competing countries jointly adopt a non-preferential taxation regime.
\end{abstract}

JEL classification: $\mathrm{F} 21 ; \mathrm{H} 21 ; \mathrm{H} 25 ; \mathrm{H} 87$

Keywords: Dynamic Tax Competition; Non-preferential regime; Preferential regime; Home Bias.

1 Introduction

This paper is a contribution to the significant theoretical literature that has focused on the comparison of tax revenues generated when countries compete to attract capital using tax rates as a strategic tool. The strategic interaction is analyzed under a preferential regime (where countries set discriminatory taxes based on mobility, nationality, vintage, etc.) and a nonpreferential regime (under which a country is restricted not to set discriminatory tax rates). In recent years, concerned by the perceived harmful effects of such preferential measures adopted by a large number of countries, several international agreements and non-binding resolutions have been adopted by the European Union (EU) and Organization for Economic Cooperation and Development (OECD) to impose restrictions on preferential taxation among member countries and to take joint action against the continuation of preferential taxation regimes by non-member countries. The primary harmful effect motivating such agreements appears to be the erosion of tax revenues and the loss of economic efficiency due to the movement of capital between jurisdictions solely to evade tax payments.

\footnotetext{
${ }^{1}$ Email: kaushal@iiserb.ac.in. Ph: +917496088192. "Competing interests: The authors declare no competing interests". I am thankful to Santanu Roy and seminar participants at ISI Delhi and JPET for their valuable comments and suggestions. I am extremely thankful to two anonymous referees and the editor Dr Rabah Amir for their valuable comments and suggestions. All remaining errors are mine.
} 
While few countries have adopted non-preferential taxation regimes, many continue to follow a discriminatory preferential taxation strategy. In this scenario, it is important to analyze whether a country has an incentive to commit to a non-preferential taxation regime even when its competitors follow the preferential taxation strategy. This also highlights the significance of cooperation between countries to jointly adopt non-preferential taxation regimes. Efforts have been made by researchers to understand the strategic forces at play when countries compete with taxes to attract capital from other jurisdictions under two taxation regimes. There is a vast literature on tax competition ${ }^{2}$ and, the effects of coordinated adoption of non-preferential regimes on tax revenues of competing countries ${ }^{3}$. There is an ongoing debate on whether competing countries earn higher tax revenues under a non-preferential or a preferential taxation regime $^{4}$. While the majority of literature on tax competition is static, we look at a dynamic twoperiod model of tax competition between two symmetric countries who compete to attract a single investor in each period, and investments are partially or fully sunk. During the initial period, competing countries simultaneously decide whether to commit to a preferential or a non-preferential taxation regime. We show that a country has an incentive to commit to a nonpreferential taxation regime even when its competitor adopts a preferential regime. When both countries adopt a preferential taxation regime, Bertrand type competition for foreign capital leads to the complete dissipation of tax revenues from foreign capital. When one country adopts a non-preferential taxation regime, competition for foreign capital reduces because the country which adopts a non-preferential taxation regime has to lower taxes on its immobile domestic capital base as well to attract foreign capital. Less competition leads to non-zero tax revenues for both countries in the later period. Because competing countries receive positive tax revenues from the new investor, the overall tax revenue is strictly positive. Because competition in the later period is lower when the initial capital is located in the country with non-preferential taxation, the country with a preferential taxation regime offers larger tax rebates in the initial period and attracts the investor. The country with a preferential taxation regime obtains tax revenue in the later period which is not too small compared to what it can earn if it attracts capital in the initial period. Therefore, a country with a preferential taxation regime is less willing to offer tax subsidies in the initial period. When both countries adopt non-preferential taxation, the competition in the later period is similar because only one country has domestic capital. But the competition during the initial period is more intense because, for both countries, the gain from attracting the capital is higher.

The literature on dynamic tax competition is scarce ${ }^{5}$. Gross, Klein, and Makris (2017) show that when capital is perfectly mobile across countries and lower tax rates during the initial period increase the available stock of capital in the later period, the capital tax rates tend to zero in the long run. In a dynamic fiscal competition model with multiple instruments, Arcalean (2019) finds that tax rates are lower under fiscal competition compared to the outcome under fiscal coordination. Our model is similar to Konrad and Kovenock (2009). They consider an infinite horizon problem where a country with a larger capital stock has agglomeration advantage. In Konrad and Kovenock (2009), both countries are either committed to non-preferential or preferential regimes and, investments are fully sunk. We allow countries to simultaneously chose between preferential or non-preferential regimes and, investments can be fully or partially sunk.

\footnotetext{
2 See for example: Janeba (1998), Zodrow and Mieszkoski (1986), Janeba and Keen (1996), Zodrow (2010), Bucovetsky (1991), Baldwin and Krugman (2004), Bucovetsky and Haufler (2007), Burbidge, Cuff and Leach (2006), Davies and Eckel (2010), Oshima (2010).

${ }^{3}$ See Wilson (1999) and more recently Keen and Konrad (2013) for a review of the literature on tax competition.

${ }^{4}$ See Keen (2001), Bucovetsky and Haufler (2007), Haupt and Peters (2005), Janeba and peters (1999), Janeba and Smart (2003), Mongrain and Wilson (2015), Kishore (2019), Kishore and Roy (2014) and, Kishore (2017) for arguments in favor and against nonpreferential taxation regimes.

${ }^{5}$ See for example Konrad and Kovenock (2009), Gross, Klein, and Makris (2017), and Arcalean (2018).
} 
A country can commit to having a preferential or a non-preferential taxation regime by signing an agreement with multinational agencies such as OECD. As discussed in Konrad and Kovenock (2009), our analysis is related to Bertrand markets with subsets of loyal customers which we discuss in more detail later. In Konrad and Kovenock (2009), one of the capital bases is immobile and, the other tax base has cost asymmetry that results from agglomeration advantages. In our model, one of the capital bases is perfectly mobile and the other tax base has cost asymmetry because the investment from the previous period is partially or fully sunk. Janeba and Smart (2003) show that in the absence of the "base effect" (fix capital base), any restrictions on preferential taxation reduce tax revenue. We generalize this result by showing that even in the absence of base effect, restrictions on preferential regimes increase tax revenue. In Janeba and Smart (2003), both capital bases are elastic even for small tax differences between the two countries. In our paper, while one of the capital bases is infinitely elastic, the other capital base is inelastic to the difference in taxes as long as the difference is not large enough.

In our paper, tax competition in the second period relates to the literature on static tax competition between asymmetric countries which analyze possible gains from jointly adopting non-preferential taxation regimes ${ }^{6}$ without any coordination on setting tax rates ${ }^{7}$. The results depend on how tax competition is modelled and the composition of tax bases. This paper looks at the competition over two tax bases which are infinitely elastic and differ in their cost of mobility. One of the capital bases has no cost of moving to either country and the other capital base faces a positive cost of mobility to another country ${ }^{8}$. Marceau, Mongrain, and Wilson (2010) find a similar result when one of the capital bases can only locate in one of the competing countries, that is, the cost of relocation to the other country is infinite.

The major contributions of this paper are the followings. First, we show that when two symmetric countries compete to attract foreign investments, a country has an incentive to unilaterally commit to a non-preferential taxation regime ${ }^{9}$. The combined tax revenues of competing countries are higher when one country commits to a non-preferential taxation regime and, the other adopts a preferential taxation regime compared to the case when both countries adopt non-preferential taxation regimes. Second, we extend the result of Haupt and Peters (2005) and Mongrain and Wilson (2015) in a dynamic setting when investors are large. We generalize the result of Haupt and Peters (2005) and show that non-preferential taxation results in larger tax revenues even when only one of the capital bases has a home bias. Moreover, the results hold even when the home bias is small and capital bases are infinitely elastic. While, Wilson (2005) shows that when one of the capital bases is perfectly mobile, and another capital base is imperfectly mobile, a preferential regime generates higher tax revenue compared to a non-preferential taxation regime. We show that the result is opposite when investors are large; a non-preferential regime generates higher tax revenue compared to a preferential regime. We also show that a non-preferential taxation scheme not only generates higher tax revenue in the later period, it also reduces tax subsidies provided to investors during the initial period.

\section{Model}

There are two identical countries/jurisdictions indexed by $i \in\{A, B\}$, who compete to attract capital from the outside their jurisdictions. The economy lasts for two periods, 1 and 2 . At the

\footnotetext{
6 See for instance Haupt and Peters (2005), Mongrain and Winson (2015), Keen (2001), Bucovetsky and Haufler (2007), Janeba and Peters (1999), Janeba and Smart (2003) and Kishore (2019).

7 See Dhillon, Perroni and Scharf (1999) for tax competition under tax coordination in the presence of private information.

${ }^{8}$ Wilson (2005) looks at the scenario when one capital base can only locate on one country and the other capital base can relocate to any country without incurring any cost.

${ }^{9}$ See Kishore and Roy (2014) and Kishore (2016) for a scenario when a single country wishes to attract heterogeneous foreign investors.
} 
beginning of period 1 ; competing countries have no domestic capital ${ }^{10}$. In each period, a single investor enters the market (who owns a unit of capital), who wishes to invest either in country $A$ or country $B$. For simplicity, we assume that outside the two competing countries the return on capital is equal to 0 . Once capital is invested in country $A$ (country $B$ ) the return on capital is equal to 1 in each period. If the investor invests in country $A$ (country $B$ ) in period 1 , he has a home bias for country $A$ (country $B$ ). Home bias is captured by the term $0 \leq F \leq 1$. Home bias can also be considered as the cost of capital relocation. If the investor invests in country $A$ (country $B$ ) in period 1 , then if country $B$ (country $A$ ) wish to attract the investor in period 2 , it has to undercut the tax rate set by country $A$ (country $B$ ) by a margin of $F$. We assume that competing countries cannot commit to future tax rates. At the beginning of each period, competing countries announce tax rates applicable for that period. At the beginning of period 1 , competing countries announce tax rates applicable for period 1 . The investor observes tax rates and decides whether to invest in country $A$ (country $B$ ) or stay outside. At the beginning of period 2 , both governments announce tax rates applicable in period 2 . The investor residing outside the two competing countries decides whether to invest in country $A$ or country $B$. The investor who is already invested either in country $A$ (country $B$ ) decides whether to relocate to country $B$ (country $A$ ) or remain invested in the initial location. If an investor had invested in country $A$ (country $B$ ) in period 1 and decide to relocate to country $B$ (country $A$ ), he incurs a cost $F$.

We analyze this two-period dynamic tax competition game when at the beginning of period 1 competing countries can either commit to a non-preferential taxation strategy, or, a preferential taxation strategy. Under a preferential taxation scheme, a government is free to set different tax rates for domestic and foreign capital. Under a non-preferential taxation scheme, a government is restricted to set an equal tax rate for domestic and foreign capital. In the present scenario, competing countries have no domestic capital at the beginning of period 1 . Hence, preferential and non-preferential taxation scheme has different implications only in period 2. If a country receives an investment in period 1 , then in period 2 , it cannot set different tax rates for the investor who invested in period 1 and the new investor in period 2 under a non-preferential taxation scheme. For simplicity, we assume that governments wish to maximize tax revenue and investors maximize their net return on capital after-tax payments. Even if a government wishes to maximize social welfare, a country would like to obtain maximum tax revenues from foreign nationals. For simplicity, we assume that governments and investors do not discount future income.

The dynamic game we analyze can be described in three stages:

Stage one: Both countries simultaneously decide whether to commit to a non-preferential regime or a preferential regime for the entire duration of the game. The same is observed by investors in both periods.

Stage two: At the beginning of period 1, both countries simultaneously announce tax rates applicable for period 1 . The maximum tax rate governments can impose is equal to 1 . Competing governments can set negative tax rates as well, that is, they can provide tax holidays during the initial period. The investor observes the tax rates and decides whether to invest in country $A$ or country $B$. Governments receive taxes at the end of period 1.

Stage three: At the beginning of period 2, both countries simultaneously announce tax rates applicable for period 2. As before, the maximum tax rate governments can impose is equal to 1 . The country which commits to a preferential taxation regime announces the tax rate applicable to domestic capital (investment from period 1 ) and the tax rate applicable to foreign capital. The

\footnotetext{
10 Konrad and Kovenock (2009) also consider a similar scenario where competing countries have no domestic capital at the beginning of period 1 . Under a non-preferential taxation scheme, if a government wishes to lower taxes to attract foreign capital, it has to lower taxes on both domestic and foreign capital. In the absence of domestic capital, there is no such cost of lower taxes on domestic capital at the beginning of period 1 . Therefore, a non-preferential taxation scheme has a maximum bite when competing countries have no domestic capital to start with.
} 
country which commits to a non-preferential taxation regime announces a single tax rate that is applicable for domestic (the investor who previously invested in the country) and foreign capital (the potential new investor). Both investors observe tax rates and make an investment decision. The new investor decides whether to invest in country $A$ or country $B$. The investor who has previously invested in country $A$ (country $B$ ) decides whether to relocate to country $B$ (country $A$ ) or remain invested in the initial location. Governments receive taxes at the end of period 2.

The equilibrium concept is the subgame-perfect Nash equilibrium. We do not consider the possibility of a mixed strategy Nash equilibrium at the initial stage when countries chose whether to commit to a non-preferential or a preferential taxation strategy. In the next section, we consider a scenario when both competing countries adopt preferential taxation regimes.

\section{Preferential Taxation}

Under a preferential taxation scheme, a country is free to set different tax rates for domestic and foreign capital. First, we look at the outcome in period 2.

\subsection{Tax Competition in Period Two under Preferential Taxation}

Without loss of generality, suppose the investor invests in country $A$ in period 1 . Under a preferential taxation scheme, country $A$ sets different tax rates for the domestic investor (the investor who previously invested in period 1 ) and foreign capital (the new investor who enters the market in period 2). Because country $B$ has no domestic capital, it sets a tax rate for foreign capital. Because the new investor has no cost of relocation to either country, competition between two countries drives down the tax rate to zero. Country $A$ sets the tax rate equal to $F$ on the investor from the earlier period. It is not beneficial for country $B$ to set a tax rate lower than 0 to attract the investor from country $A$. Therefore, country $A$ retains the investor from period 1 and obtains tax revenues equal to $F$. Because the tax rate on the new investor is equal to 0 , country $B$ does not receive a positive tax revenue in period 2 . Lemma 1 states this result formally.

Lemma 1 The equilibrium tax revenues of country $A$ (where the investor invests in period 1) and country $B$ in period 2 are $F$ and 0 , respectively. In the unique pure strategy Nash equilibrium, country $A$ sets the tax rates $F$ and 0 respectively, on the investors from period 1 and period 2. Country $B$ sets the tax rate equal to 0 on both investors.

\subsection{Tax Competition in Period one under Preferential Taxation}

From Lemma 1, it is clear that a country that attracts the investor in period 1 also receives a positive tax revenue in period 2 . On the other hand, a country that fails to attract the investor in period 1 receives 0 as tax revenue in period 2 . Hence, in period 1 , competing countries offer a tax subsidy equal to the possible gain in period 2 from attracting the investor in period 1 . Lemma 2 states the result. The proof is trivial.

Lemma 2 Competing countries offer a tax subsidy equal to $F$ in period 1 . The tax revenue of competing countries is equal to 0 .

\section{Non-preferential Taxation}

In this section, we analyze the game under a non-preferential taxation scheme. Under a nonpreferential regime, competing countries are restricted to set an equal tax rate on the investor from period 1 and the new investor in period 2 . First, we look at the outcome in period 2. 


\subsection{Tax Competition in Period Two}

Without loss of generality, suppose the investor invests in country $A$ in period 1 . Under a nonpreferential taxation scheme, country $A$ is restricted to set an equal tax rate on the investor who previously invested in period 1 and the new investor. Suppose at the beginning of period 2 , country $A$ and country $B$ set the tax rates $t_{A 2}$ and $t_{B 2}$, respectively. The tax revenue of country $A$ in period $2\left(T R_{A 2}\right)$ is:

$$
T R_{A 2}=\left\{\begin{array}{lr}
2 t_{A 2} & \text { if } t_{A 2} \leq t_{B 2} \\
t_{A 2} & \text { if } t_{B 2}<t_{A 2} \leq t_{B 2}+F \\
0 & \text { if } t_{A 2}>t_{B 2}+F
\end{array}\right.
$$

If country $A$ sets the tax rate $t_{A 2}>t_{B 2}+F$ then country $B$ attracts the new investor as well as the investor from country $A$. If country $A$ sets $t_{A 2}$ such that $t_{B 2}<t_{A 2}<t_{B 2}+F$, country $B$ attracts the new investor in period 2 but country $A$ is able to keep its domestic investor because of home bias. When $t_{A 2}<t_{B 2}$, country $A$ is also able to attract the new investor as well. Similarly, the tax revenue of country $B$ in period $2\left(T R_{B 2}\right)$ is:

$$
T R_{B 2}=\left\{\begin{array}{lr}
2 t_{B 2} & \text { if } t_{B 2}<t_{A 2}-F \\
t_{B 2} & \text { if } t_{A 2}-F \leq t_{B 2}<t_{A 2} \\
0 & \text { if } t_{B 2} \geq t_{A 2}
\end{array}\right.
$$

Note that country $B$ is a more aggressive competitor in period 2. Country $B$ has to undercut the tax rate of country $A$ by a small margin to attract the new investor. Country $B$ can also undercut country $A$ by a margin of $F$ to attract the investor from country $A$. We assume that when an investor is indifferent between country $A$ and country $B$, the investor chooses to invest in country A. As noted in Fisher and Wilson (1995), equilibriums of the game do not change if equality is replaced with inequality in the payoff function. Lemmas 3-6 describe the equilibrium outcomes.

Lemma 3 In the subgame starting at the beginning of period 2, when both countries adopt nonpreferential regimes at the earlier stage, there is no pure strategy Nash equilibrium when $F>0$. However, a unique mixed strategy Nash equilibrium exists for all values of $F>0$. When $F=0$, there is a unique pure strategy Nash equilibrium where both countries set the tax rate equal to 0.

\section{Proof. See Appendix A.}

When $F>0$, a Nash equilibrium does not exist where countries set an equal tax rate. In this case, a country can reduce the tax rate marginally and attract the new investor with probability one. An asymmetric pure strategy Nash equilibrium also does not exist where countries set different tax rates. In this case, a country with a lower tax rate attracts the new investor with probability one. If the investor from period 1 is also initially located in the country with a lower tax rate then it has an incentive to increase its tax rate. If the investor from period 1 is initially located in the country with a higher tax rate, then the country with a lower tax rate has an incentive to increase its tax rate if it is not able to attract the old investor. On the other hand, if the country with a lower tax rate attracts the investor from the competing country, then the other country has an incentive to lower its tax rate to keep its domestic investor. Therefore, neither symmetric nor asymmetric pure strategy Nash equilibrium exists. Given a pure strategy Nash equilibrium does not exist, we analyze Nash equilibrium in mixed strategies.

A mixed strategy Nash equilibrium of this type has many parallels in the literature. The equilibrium can be used to analyze a scenario when some consumers have a switching cost while 
others can freely choose between different suppliers. Klemperer (1995) considers the case when some consumers have infinite switching cost, that is, they are completely tied with one supplier. Here, we allow consumers to switch suppliers by incurring a certain positive cost of switching. Konrad and Kovenock (2009) consider a scenario when some consumers have infinite switching cost and the others can switch by incurring a positive cost. Therefore, competitors only compete for a fraction of consumers who can switch. In our case, competitors compete for all consumers. It is noteworthy that the equilibrium price can be a lot higher than the switching cost even when the switching cost is small. Wilson (2005) also analyzed a mixed strategy Nash equilibrium when one of the capital bases is perfectly mobile, and the other capital base is completely immobile.

The equilibrium we describe is a special case of mixed strategy Nash equilibrium analyzed in Fisher and Wilson (1995). Fisher and Wilson (1995) consider competition between two firms when two countries impose tariffs, and the total demand is a function of price. When the total demand is constant, and only one of the two countries imposes a tariff then the equilibrium is similar to ours. Our proof of existence and uniqueness of mixed strategy Nash equilibrium follows directly Fisher and Wilson (1995).

Lemmas 4-6 describe the mixed strategy Nash equilibrium for different costs of mobility (home bias) captured by the variable $F$. Equilibrium strategies depend on whether home bias is small, large, or, in an intermediate range. Lemma 4 describes a mixed strategy Nash equilibrium when home bias is relatively large, i.e., $F \geq \frac{2}{3}$.

Lemma 4 In the subgame starting at the beginning of period 2 when both countries adopt nonpreferential regimes at the earlier stage, a unique mixed strategy Nash equilibrium exists when $\frac{2}{3} \leq F$. In the mixed strategy Nash equilibrium, tax revenues of country $A$ and country $B$ are 1 and $\frac{1}{2}$, respectively. Country $A$ has a probability mass of $\frac{1}{2}$ at the supremum of the support. The distribution of taxes of country $\mathrm{A}\left(\mathcal{F}_{A}\left(t_{A 2}\right)\right)$ and country $\mathrm{B}\left(\mathcal{F}_{B}\left(t_{B 2}\right)\right)$ are

$$
\begin{gathered}
\mathcal{F}_{A}\left(t_{A 2}\right)=\left\{\begin{array}{cc}
0 & t_{A 2}<\frac{1}{2} \\
1-\frac{1}{2 t_{A 2}} & \frac{1}{2} \leq t_{A 2}<1 \\
1 & t_{A 2}>1
\end{array}\right. \\
\mathcal{F}_{B}\left(t_{B 2}\right)= \begin{cases}0 & t_{B 2}<\frac{1}{2} \\
2-\frac{1}{t_{B 2}} & \frac{1}{2} \leq t_{B 2} \leq 1 \\
1 & t_{B 2}>1\end{cases}
\end{gathered}
$$

Proof. See Appendix A.

Lemma 4 states that when the home bias is large enough, competing countries receive strictly positive tax revenues in period 2. Equilibrium tax revenues of competing countries do not depend on the home bias. When $F$ is large $\left(F \geq \frac{2}{3}\right)$, the mixed strategy Nash equilibrium is similar to Varian (1980) and Narasimhan (1988). When $F=1$, the mixed strategy Nash equilibrium is exactly similar to Narasimhan (1988). Country $A$ receives the tax revenue equal to 1 by setting the tax rate equal to 1 on the investor from period 1 and forgo the new investor. Hence, the minimum 
tax rate country $A$ set is equal to $\frac{1}{2}$ because even if country $A$ attracts the new investor with probability 1 at a tax rate lower than $\frac{1}{2}$, its tax revenue is lower than 1 . Note that as long as $\frac{2}{3} \leq$ $F$, the mixed strategy Nash equilibrium remains the same because country $B$ has to set a tax rate lower than $1-F$ to attract the investor from country $A$ which is too low to be beneficial. The interesting feature of this equilibrium is that both countries receive the new investor with a positive probability and, country $A$ retains the investor who previously invested in period 1 . Lemma 5 describes the outcome when $F$ is relatively smaller. Let us define $\phi$ and $m$ as

$$
\phi \equiv \frac{1}{2 F}\left(1+3 F-\sqrt{6 F+F^{2}+1}\right)
$$

and

$$
m \equiv \frac{\phi+F-1}{1-F} .
$$

Below we show that $0<\phi<F$, and $0<m<1$. Let $\Delta$ be the value of $F$ such that $1-F=$ $\phi$. The value of $\Delta$ is approximately equal to 0.54369 which is strictly less than $\frac{2}{3}$.

Lemma 5 In the subgame starting at the beginning of period 2 when both countries adopt nonpreferential regimes at the earlier stage, a unique mixed strategy Nash equilibrium exists when $\Delta<F<\frac{2}{3}$. The equilibrium tax revenues of country $\mathrm{A}$ and country $\mathrm{B}$ are $\frac{\phi}{1-\phi}$ and $\phi$, respectively. Country $\mathrm{A}$ has a positive probability mass of $m$ at the supremum of its support. The distribution of taxes of country $\mathrm{A}\left(\mathcal{F}_{A}\left(t_{A 2}\right)\right)$ and country $\mathrm{B}\left(\mathcal{F}_{B}\left(t_{B 2}\right)\right)$ are

$$
\begin{gathered}
\mathcal{F}_{A}\left(t_{A 2}\right)=\left\{\begin{array}{cl}
0, & t_{A 2}<\phi \\
1-\frac{\phi}{t_{A 2}}, & \phi \leq t_{A 2} \leq \frac{\phi}{1-\phi} \\
\frac{2\left(t_{A 2}-F\right)-\phi}{t_{A 2}-F}, & \frac{\phi}{1-\phi} \leq t_{A 2} \leq 1 \\
1, & t_{A 2}>1
\end{array}\right. \\
\mathcal{F}_{B}\left(t_{B 2}\right)=\left\{\begin{aligned}
0, & t_{B 2}<\frac{\phi}{1-\phi}-F \\
\frac{\left(t_{B 2}+F\right)(1-\phi)-\phi}{\left(t_{B 2}+F\right)(1-\phi)}, & \frac{\phi}{1-\phi}-F \leq t_{B 2} \leq 1-F \\
2-\frac{\phi}{(1-\phi) t_{B 2}}, & \phi \leq t_{B 2} \leq \frac{\phi}{1-\phi} \\
1, & t_{B 2}>\frac{\phi}{1-\phi}
\end{aligned}\right.
\end{gathered}
$$

Proof. See Appendix B.

When country $A$ sets a tax rate in the range $\left[\frac{\phi}{1-\phi}, 1\right]$, it is beneficial for country $B$ to undercut the tax rate of country $A$ by a margin of $F$ and attract the new investor and the investor who previously invested in country $A$. When country $A$ sets a relatively lower tax rate in the range $\left[\phi, \frac{\phi}{1-\phi}\right]$, it is not beneficial for country B to undercut the tax rate of country A by a margin of $F$. In this scenario, both countries compete for the new investor. Note that $F$ is equal to $\Delta$ when $1-$ $F=\phi$. The support of the mixed strategy Nash equilibrium of country $B$ is disjoint because country $A$ has a probability mass at the supremum of its support. Therefore, when country $B$ lowers its tax rate from $\frac{\phi}{1-\phi}$ to $1-F$, it undercuts country $A$ with a discrete positive probability. 
Figure 1 depicts the equilibrium tax revenues of competing countries described in Lemma 5 . The second line from the top is $\frac{\phi}{1-\phi}$, the line at the bottom is $\phi$, the second line from the bottom is $F$ and, the line at the top is $2 F$. We can see that $2 F>\frac{\phi}{1-\phi}>F$ and $0<\phi<F$.

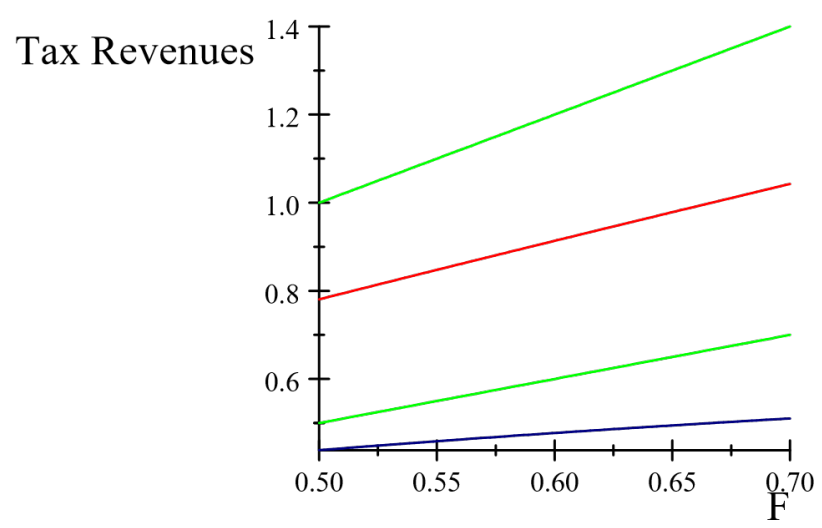

Figure 1: Equilibrium tax revenues of competing countries when $\Delta \leq F \leq \frac{2}{3}$.

Below Lemma 6 describes the equilibrium outcome when $F$ is very small, i. e. , $0<F<\Delta$. Let us define $\theta=\left(\Delta^{2}+\Delta\right)$. Note that $1>\theta>\Delta>0$. The mixed strategy Nash equilibrium described in Lemma 6 is similar to the one described in Lemma 5 . When $F$ is lower, the support of the mixed strategy Nash equilibrium of country $B$ is also not disjoint.

Lemma 6 In the subgame starting at the beginning of period 2 when both countries adopt nonpreferential regimes at the earlier stage, a unique mixed strategy Nash equilibrium exists when $0<$ $F<\Delta$. In the mixed strategy Nash equilibrium, tax revenues of country $\mathrm{A}$ and country $\mathrm{B}$ are $(1+\Delta) F$ and $\theta F$, respectively. The distribution of taxes of country $A\left(\mathcal{F}_{A}\left(t_{A 2}\right)\right)$ and country $\mathrm{B}$ $\left(\mathcal{F}_{B}\left(t_{B 2}\right)\right)$ are

$$
\begin{aligned}
& \mathcal{F}_{A}\left(t_{A 2}\right)=\left\{\begin{aligned}
0, & t_{A 2}<\theta F \\
1-\frac{\theta F}{t_{A 2}}, & \theta F \leq t_{A 2} \leq(1+\Delta) F \\
2-\frac{\theta F}{t_{A 2}-F}, & (1+\Delta) F \leq t_{A 2} \leq(1+\theta) F \\
1, & t_{A 2}>(1+\theta) F
\end{aligned}\right. \\
& \mathcal{F}_{B}\left(t_{B 2}\right)=\left\{\begin{aligned}
0, & t_{B 2}<\Delta F \\
1-\frac{(1+\Delta) F}{t_{B 2}+F}, & \Delta F \leq t_{B 2} \leq \theta F \\
2-\frac{(1+\Delta) F}{t_{B 2}}, & \theta F<t_{B 2} \leq(1+\Delta) F \\
1, & t_{B 2}>(1+\Delta) F
\end{aligned}\right.
\end{aligned}
$$

Proof. See Appendix B.

The intuition behind the mixed strategy Nash equilibrium described in lemma 6 is similar to the one already described in lemma 5 . The distributions of taxes described by equations (9) and (10) are continuous when $\theta=\Delta^{2}+\Delta$. When country $A$ sets a relatively high tax rate in the range $[(1+\Delta) F,(1+\theta) F]$, it is beneficial for country $B$ to undercut by a discrete margin to attract the investor from country $A$ and the new investor. When country $A$ sets a lower tax rate in the range $[\theta F,(1+\Delta) F]$ then it is not beneficial for country $B$ to undercut by a discrete margin to attract the investor who had previously invested in country $A$. In this scenario, both countries 
compete for the new investor. Note that there is no probability mass anywhere on the supports of either country. The tax revenue of both countries decreases as $F$ decreases.

\subsection{Tax Competition in Period One}

As evident from lemmas 3-6, the country which attracts the investor in period 1 also receives a larger tax revenue in period 2 . Without a loss of generality, suppose country $A$ attracts the investor in period one. Suppose also that the tax revenue of country $A$ and country $B$ in period 2 are $T R_{A 2}$ and $T R_{B 2}$, where $T R_{A 2}>T R_{B 2}$ when $F>0$, and $T R_{A 2}=T R_{B 2}=0$ when $F=0$. When $F=0$, the tax revenue of both countries is equal to 0 in period 2. No country has an incentive to provide a tax rebate in period 1 to attract the investor. Therefore, both countries set the tax rate equal to 0 in period 1 . When $F>$ 0 , competing countries set the tax rate equal to $-\delta$, where $\delta \equiv\left(T R_{A 2}-T R_{B 2}\right)>0$. If a country sets a tax rate greater than $-\delta$, then the competing country has an incentive to set a lower tax rate to attract the investor in period 1 . Similarly, no country has an incentive to set a tax rate smaller than $-\delta$ because even when it is successful in attracting the investor in period 1 , the combined tax revenue from two periods is smaller. Lemma 7 describes the outcome in period 1.

Lemma 7. Starting from the subgame where both countries adopt non-preferential taxation regimes, the equilibrium tax revenue of competing countries is equal to

$$
T R=\left\{\begin{array}{cr}
0, & F=0 \\
\theta \Phi, & 0<F<\Delta \\
\Phi, & \Delta \leq F<\frac{2}{3} \\
\frac{1}{2}, & F \geq \frac{2}{3}
\end{array}\right.
$$

The equilibrium tax rate $t_{1}$ in period one is

$$
t_{1}=\left\{\begin{array}{lr}
0, & F=0 \\
-\left(1-\Delta^{2}\right) F, & 0<F<\Delta \\
-\frac{\Phi^{2}}{1-\Phi}, & \Delta \leq F<\frac{2}{3} \\
-\frac{1}{2}, & F \geq \frac{2}{3}
\end{array}\right.
$$

Proof. The proof is evident once we observe that the difference in tax revenue of competing countries in period 2 is 0 when $F=0, \frac{1}{2}$ when $F \geq \frac{2}{3^{\prime}}-\frac{\phi^{2}}{1-\phi}$ when $\Delta \leq F<\frac{2}{3^{\prime}}$ and $\left(1-\Delta^{2}\right) F$ when $0<F<\Delta$.

\section{$5 \quad$ Mixed Taxation Regimes}

In a mixed taxation regime, one of the competing countries adopts a non-preferential taxation regime and, the other adopts a preferential taxation regime. We observed that when both countries adopt a non-preferential taxation regime, the equilibrium tax revenues of competing countries are strictly positive when the cost of mobility is strictly positive. On the other hand, the tax revenue of competing countries is equal to 0 when both countries adopt a preferential taxation regime. Therefore, competing countries have an incentive to jointly adopt a nonpreferential taxation regime. In this section, we analyze outcomes under a mixed taxation regime.

Under a mixed taxation regime, the outcome of competition in period 2 depends on whether the country with a non-preferential taxation regime or the country with a preferential taxation 
regime attracts the investor in period 1 . If the country with a non-preferential taxation regime attracts the investor in period 1 , the outcomes of tax competition in period 2 under a mixed taxation regime and when both countries adopt a non-preferential taxation regime are equal. Moreover, if the country with a preferential taxation regime attracts the investor in period 1 , the outcomes of tax competition in period 2 are equal to the outcomes when both countries adopt a preferential taxation regime. Observing these similarities, we omit the discussion of period 2.

Consider a mixed taxation regime where country A adopts a non-preferential while country $B$ adopts a preferential taxation regime. We observed that the outcome of period 2 depends critically on whether country $A$ or country $B$ attracts the investor in period 1 . Country $B$ receives $F$ in tax revenue in period 2 when it attracts the investor in period 1 . When country $B$ fails to attract the investor in period 1 , it receives a positive amount (when $\mathrm{F}$ is strictly positive) as tax revenue in period 2 which is strictly less than $F$. When country $A$ attracts the investor in period 1 its tax revenue in period 2 is larger than $F$ when $F>0$. If country A fails to attract the investor in period 1 its tax revenue in period 2 is 0 . As country $A$ gains more in period 2 when it attracts the investor in period 1 , it offers a larger tax rebate in period 1 compared to country $B$, and the investor invests in country $A$.

Moreover, when both countries jointly adopt a non-preferential taxation regime, the equilibrium tax revenue of competing countries over two periods is equal to the tax revenue a country earns in period 2 when it fails to attract the investor in period 1 . Therefore, in a mixed strategy, the tax revenue of a country that adopts a preferential taxation regime is equal to the equilibrium tax revenue of a country when they jointly adopt a non-preferential taxation regime.

Lemma 8 below describes the equilibrium of the game when country $A$ adopts a nonpreferential, and country $B$ adopts a preferential taxation regime.

Lemma 8. Starting at a subgame where country $A$ adopts a non-preferential taxation regime and, country $B$ adopts a preferential taxation regime, in a unique subgame-perfect Nash equilibrium, country $A$ offers a larger tax subsidy relative to country $B$ and attracts the investor in period 1 . The tax revenue of country $B$ is equal to that a country earns when two countries jointly adopt a non-preferential taxation regime. The tax revenues of competing countries are strictly positive when $F>0$.

\section{Comparison}

We observed that when both countries commit to preferential taxation regimes then in a unique pure strategy Nash equilibrium, both countries earn zero as tax revenues. When both countries adopt a non-preferential taxation regime, then in a unique subgame-perfect Nash equilibrium competing countries earn strictly positive tax revenues when the cost of capital relocation is strictly positive. Under a mixed taxation regime, that is, one country adopts a non-preferential and the other adopt a preferential taxation regime, both countries earn strictly positive tax revenues as long as the cost of capital relocation is strictly positive. Moreover, the tax revenue of the country which adopts a preferential taxation regime is equal to what a country earns when both jointly adopt non-preferential taxation regimes.

Suppose two countries jointly adopt non-preferential taxation regimes. If a country deviates and adopt a preferential taxation regime, its tax revenue remains unchanged. Therefore, starting from a scenario where both countries have non-preferential taxation regime, no country has an incentive to deviate and adopt a preferential taxation regime. 
Now, consider a mixed taxation regime where country $A$ adopts a non-preferential and country $B$ adopts a preferential taxation regime. If country $A$ deviates and adopts a preferential taxation regime. From Lemma 8, we know that under a mixed taxation regime the tax revenue of country $A$ is strictly positive as long as the cost of capital relocation is positive. On the other hand, the tax revenue of country $A$ is zero when both countries adopt a preferential taxation regime. Therefore, country $A$ has no incentive to deviate and adopt a preferential taxation regime. Suppose country $B$ deviates and adopt a non-preferential taxation regime. From Lemma 8 , the tax revenue of country $B$ remains unchanged. Therefore, country $B$ has no incentive to deviate and adopt a non-preferential taxation regime.

From the above discussion we conclude that we have two subgame-perfect equilibria of the game. In one of the subgame-perfect equilibria, one country adopts a non-preferential taxation while the competitor adopts a preferential taxation regime. In other subgame-perfect equilibria, competing countries jointly adopt a non-preferential regime. A scenario where two countries jointly adopt a preferential taxation is not a subgame-perfect equilibrium. We do not have a precise prediction whether both countries jointly adopt a non-preferential regime, or, only one of the competing countries adopts a non-preferential taxation regime. Below, proposition 1 describes the subgame perfect outcome of the game. The subgame-perfect Nash equilibria have pure strategies at the initial stage where competing countries decide whether to adopt a nonpreferential or a preferential taxation regime. This is the main result of the paper.

Proposition 1. The game has two types of subgame-perfect Nash equilibria. In one subgameperfect Nash equilibrium, one country adopts a non-preferential and, the other adopts a preferential taxation regime. In other subgame-perfect Nash equilibrium, both countries jointly adopt non-preferential taxation regimes. In both subgame-perfect equilibria, tax revenues of competing countries are strictly positive when the cost of capital relocation is strictly positive.

\section{Role of Positive Domestic Capital}

It is also important to discuss the role of competing countries starting with having no domestic capital. In both countries start with positive domestic capital and, both countries adopt a preferential taxation strategy then the outcome does not depend on the initial capital and, as before, Bertrand type competition for the foreign capital drive down tax revenues from foreign capital equal to zero. Let us consider an interesting case when one country adopts a nonpreferential and, the other adopts a preferential taxation regime. The outcomes of the game do not change when the country with a preferential taxation regime has positive domestic capital except that the tax revenue from domestic capital is added to the total tax revenue. Let us see what happens when the country with a non-preferential taxation strategy has positive domestic capital. The gain to the country in the later period from attracting new investments in the initial period remains the same. But, because the country has positive domestic capital, the cost of offering a tax subsidy to new investors is higher because it sets an equal tax rate for domestic and foreign capital. At the same time, if the country with a non-preferential taxation regime attracts the investor in period 1 , then tax revenues of the other country from new investments increase because competition for foreign capital in the later period is smaller. Therefore, the outcome depends on which of the two effects dominate as long as the tax rebate offered to the investor in the initial period is strictly positive, that is, the tax rate in the initial period is negative. A similar argument can also be given when both countries adopt a non-preferential taxation regime. As long as the new capital is perfectly mobile, the gain in period 2 from attracting the new investor in period 1 is the same. The tax revenue in period 2 of the losing country also increases with the size of the domestic capital of the winner. Therefore, the smaller of the two countries are also less willing to undercut the other country during the initial period. The bigger 
of the two countries are also willing to offer less tax subsidy during the initial period as the size of the domestic capital base increases. Therefore, it is not clear whether a country with a larger capital base attracts the investor during the initial period. But if the size of the domestic tax base is so large that the minimum tax rate a country with a non-preferential regime can set to attract the new investor is strictly positive, that is, the tax rate in period 1 is strictly positive, a country with a preferential taxation regime can undercut the tax rate of the country with a nonpreferential regime and receive positive tax revenues from the investments in the initial period as well. In this scenario, having a preferential taxation regime is better. Therefore, it is reasonable to argue that if competing countries start with a large domestic capital, a country would prefer having a preferential taxation strategy and, it would want its competitor to adopt a nonpreferential strategy.

\section{Conclusion}

In a dynamic two-period model of tax competition between two symmetric countries, where an investor has a home bias for the country where he/she invests in the initial period, we show that a country has an incentive to commit to a non-preferential taxation regime even when its competitor adopts a preferential taxation strategy. Moreover, a scenario where both countries jointly adopt non-preferential taxation regimes is also a subgame-perfect Nash equilibrium. Therefore, the model predicts that at least one of the countries adopts a non-preferential taxation regime. The gain from having a non-preferential regime is strictly increasing with home bias as long as the home bias is not large enough. When the home bias is above a critical level, the gain from having a non-preferential agreement is independent of home bias. While the literature on tax competition has identified that "home bias" can make non-preferential taxation preferable to a preferential regime when investors are small with heterogeneous home bias, we show that even when investors are large with a discrete home bias, a non-preferential regime generates higher tax revenue compared to a preferential regime. Moreover, we show that even when only one of the capital bases has a home bias, a non-preferential regime generates higher tax revenue compared to a preferential regime. This paper also quantifies the gain from a nonpreferential regime with a parameter that captures home bias and provides clear comparative statics.

\section{References}

[1] Arcalean, C. (2019). Dynamic fiscal competition: A political economic theory. Journal of Public Economics 164, 211-224.

[2] Baldwin, R., Krugman, P. (2004). Agglomeration, integration and tax harmonization. European Economic Review 48, 1-23.

[3] Besley, T., Persson, T. (2009). The Origins of State Capacity: Property Rights, Taxation, and Politics. The American Economic Review 99, 1218-1244.

[4] Bucovetsky, S. (1991). Asymmetric Tax Competition. Journal of Urban Economics 30, 167181.

[5] Bucovetsky, S., Haufler, A. (2007). Preferential tax regimes with asymmetric countries. National Tax Journal 60, 789-795.

[6] Burbidge, J., Cuff, K., Leach, J. (2006). Tax competition with heterogeneous rms. Journal of Public Economics 90, 533-549. 
[7] Davies, R., Eckel, C. (2010). Tax competition for heterogeneous firms with endogenous entry. American Economics Journal 2, 77-102.

[8] Dhillon, A., Perroni, C., Scharf, K. (1999) Implementing Tax Coordination. Journal of Public Economics 72, 243-268.

[9] Fisher, E., Wilson, C. (1995). Price competition between two International Firms Facing Tariffs. International Journal of Industrial Organization 13, 67-87.

[10] Gross, T., Klein, P., Makris, M. (2017) Dynamic Capital Tax Competition under the Source Principle. Working Paper.

[11] Haupt, A., Peters, W. (2005). Restricting preferential tax regimes to avoid harmful tax competition. Regional Science and Urban Economics 35, 493-507.

[12] Janeba, E., Keen, M. (1996). Tax competition and Leviathan. European Economic Review, 40, pp. 113-134.

[13] Janeba, E. (1998). Tax competition in imperfectly competitive markets. Journal of International Economics, 44, 135-153.

[14] Janeba, E., Schjelderup, G. (2009). The welfare Effect of Tax Competition Reconsidered: Politicians and Political Institutions. The Economic Journal, 119, 1143-1161.

[15] Janeba, E., Smart, M. (2003). Is targeted tax competition less harmful than its remedies?. International Tax and Public Finance 10, 259-280.

[16] Janeba, E., Peters, W. (1999). Tax evasion, tax competition and the gains from nondiscrimination: the case of interest taxation in Europe. Economic Journal 93-101.

[17] Keen, Michael. (2001). Preferential Regimes Can Make Tax Competition Less Harmful. National Tax Journal 54, 757-62.

[18] Keen, M. and Konard, K. (2013). The theory of international tax competition and coordination, in: Auerbach, A.J., Chetty, R., Feldstein, M. and Saez, E. (Eds.). Handbook of Public Economics, Volume 5 (Elsevier, Amsterdam, Oxford), 257-328.

[19] Kishore, K., Roy, S. (2014). Dynamic inconsistency and non-preferential taxation of foreign capital. Economics Letters 124, 88-92.

[20] Kishore, K. (2017). Dynamic Inconsistency and Preferential Taxation of foreign capital. International Tax and Public Finance 24, 381-396.

[21] Kishore, K. (2019). Tax Competition, Imperfect Capital Mobility and the gain from nonpreferential agreements. Journal of International Trade and Economic Development 28, 755774.

[22] Klemperer (1995). Competition when Consumers Have Switching Costs: An Overview with Applications to Industrial Organization, Macroeconomics and International Trade. Review of Economic Studies 62, 515-539.

[23] Konrad, K., Kovenock, D. (2009). Competition for FDI with vintage investment and agglomeration advantages. Journal of International Economics 79, 230-237.

[24] Marceau N., Mongrain, S., Wilson, J. (2010). Why Do Most Regions Set High Tax Rates on Capital?. Journal of International Economics 80, 249-259. 
[25] Narasimhan, C. (1988). Competitive promotional strategies. Journal of Business 61, 427-449.

[26] Oshima, K. (2010). Preferential tax regimes and agglomeration economies. Journal of the UMDS - Information, Economics \& Management Science 19, 49-59.

[27] OECD. (2006). The OECD s Project on Harmful Tax Practices: 2006 Update On Progress in Member Countries.

[28] Mongrain, S., Wilson, J. (2018). Tax competition with heterogeneous capital mobility. Journal of Public Economics 167, 177-189.

[29] Steeve, M., Wilson, J. (2015). Tax Competition with Heterogeneous Capital Mobility. CESifo Working Paper Series No. 5688.

[30] Varian, H. (1980). A Model of Sales. The American Economic Review, 70, 651-659.

[31] Wilson, J. (2005). Tax competition with and without Preferential Treatment of a HighlyMobile Tax Base. In J. Alm, J. Martinez-Vasquez, and M. Rider, Editors, The Challenge in Tax Reform in a Global Economy,

Springer.

[32] Wang, X. (2004). Tax evasion, tax competition and gains from nondiscrimination with equilibrium mixed strategies. Economics Letters 83, 377-381.

[33] Wilson, J. (1999). Theories of tax competition. National Tax Journal 52, 269-304.

[34] Zodrow, G., Mieszkowski, P. (1986). Pigou, Tiebout, Property Taxation and the Underprovision of Local Public Goods. Journal of Urban Economics, 19, 356-370.

[35] Zodrow, G. (2010). Capital Mobility and Capital Tax Competition. National Tax Journal 63, 865-902.

\section{Appendix A}

Proof of Lemma 3. Without a loss of generality, suppose country $A$ attracts the investor in period 1. Suppose there is a symmetric pure strategy Nash equilibrium where both competing countries set an equal tax rate $t$. Note that $t$ should be greater than 0 because country $A$ can receive a positive tax revenue by setting a greater tax rate and receive taxes only from its domestic investor. For any $t>0$, country B would lower its tax rate slightly and attract the new investor with probability one. Hence, there is no symmetric pure strategy Nash equilibrium. Suppose there is an asymmetric pure strategy Nash equilibrium where country $\mathrm{A}$ and country $\mathrm{B}$ sets $t_{A}$ and $t_{B}$ such that $t_{A}>t_{B}>0$. In this scenario, country $B$ attracts the new investor, but it has an incentive to increase its tax rate. Similarly, there is no possibility of a pure strategy Nash equilibrium where $0<t_{A}<t_{B}$.

Proof of Lemma 4. The proof follows from Narasimhan (1988). This is also a special of mixed strategy Nash equilibrium discussed in Fisher and Wilson (1995). Without loss of generality, suppose country $A$ attracts the investor in period one. Note that country $A$ can undercut country $B$ by a small margin and attract the new investor. Country $B$ can undercut $A$ by a small margin and attract the new investor. Country $B$ can undercut country $A$ by a margin of $F$ and attract the investor located in country A.

Step 1. First, we show that when $F \geq \frac{2}{3}$, country $\mathrm{B}$ has no incentive to undercut country A by a margin of $F$. To prove the claim, suppose country $A$ sets the tax rate equal to 1 . 
Country $B$ can set a tax rate marginally lower than 1 and obtain 1 as tax revenue. Suppose country $\mathrm{B}$ undercuts by a margin of $F$ and attracts both investors. The tax revenue of country in this case is equal to $2(1-F)<1$ when $F>\frac{1}{2}$. It follows that country $B$ has no incentive to undercut by margin of $F$. Therefore, both countries wish to undercut its competitor by a small margin to attract the new investor when $F \geq \frac{2}{3}$.

Step 2. Now we follow Narasimhan (1988) to show that the supports of any mixed strategy Nash equilibrium are convex. Suppose country $i$ and country $j$ randomize over $S_{i}^{*}$ and $S_{j}^{*}$ in a mixed strategy Nash equilibrium. First, we show that strategy sets $S_{A}^{*}$ and $S_{B}^{*}$ are convex. We prove by showing that there are no holes in $T=S_{i}^{*} \cap S_{j}^{*}$ and then showing that there are no holes in $T^{\prime}=S_{i}^{*}-S_{i}^{*} \cap S_{j}^{*}$. Let $t^{\prime}=\inf (T)$ and $t^{\prime \prime}=\sup (T)$. To show that $T$ is convex, we show that there are no "holes" in $T$. That is, there is no interval $I=\left(t^{k}, t^{h}\right)$ such that, for $t^{\prime}<t^{k}<t^{h}<t^{\prime \prime}$ and $t \in I, t \notin T$. This could happen when one of the countries has support over the interval $I$ and the other one does not or when neither country has support over the interval $I$. We show that neither of these two is possible.

First note that if the $i$ th country sets $t \in I$ with probability zero, then so does the $j$ th country. To see this, let $t^{1}$ and $t^{2}$ be defined as

$$
\begin{gathered}
t^{1} \in S_{i}^{*} \text { and } t^{1}=\sup \left\{t \mid t<t^{k}\right\}, \\
t^{2} \in S_{i}^{*} \text { and } t^{2}=\inf \left\{t \mid t>t^{h}\right\} .
\end{gathered}
$$

We define $\alpha=1$ when $j=A$, and $\alpha=0$ when $j=B$. Since the tax revenue of the $j$ th country, when it charges $t_{j}=\left\{t_{j} . \alpha+\left[1-F_{i}\left(t_{j}\right)\right] t_{j}\right\}$, is increasing in $t_{j}$ for $t_{j} \in I$, country $j$ is better off charging $t^{2}$ with probability $\left[F_{j}\left(t^{2}\right)-F_{j}\left(t^{1}\right)\right]$ and no mass over the set $I$.

Now consider the case that neither country is randomizing over the set $I$. The tax revenue of the $j$ th country when she charges $t^{1}$ is

$$
t^{1} . \alpha+\left[1-F_{i}\left(t^{1}\right)\right] t^{1} .
$$

Next consider the tax revenue that would accrue if the $j$ th country charges $t^{h}$. The tax revenue equals

$$
t^{h} \cdot \alpha+\left[1-F_{i}\left(t^{h}\right)\right] t^{h}
$$

But, since $F_{i}\left(t^{h}\right)=F_{i}\left(t^{k}\right)=F_{i}\left(t^{1}\right)$, the revenue obtained by charging $t^{h}$ are strictly greater than the revenue obtained by charging $t^{1}$, contradicting the assumption of an equilibrium.

No Holes in $T^{\prime}$. Here, $T^{\prime}$ corresponds to the set of taxes charged by $i$ but not by $j$. Once again, we define $t^{\prime}=\inf \left(T^{\prime}\right)$ and $t^{\prime \prime}=\sup \left(T^{\prime}\right)$. Note that either $t^{\prime \prime}<\inf \left(S_{j}^{*}\right)$ or $t^{\prime}>$ $\sup \left(S_{j}^{*}\right)$. Note that $T^{\prime}$ cannot contain any holes. If it did, country $i$ could strictly make itself better off by moving the mass from the lower end of the hole to the upper end since by doing so it does not lose the investor but charges a higher tax rate.

Step 3. Next, we show that neither country can have a mass point at the interior or at the lower boundary of the other's support, nor can either country have a mass point at the upper boundary of other's support if that boundary is a mass point for the other country.

Let $t_{i}^{\prime}=\inf \left(S_{i}^{*}\right)$ and $t_{i}^{\prime \prime}=\sup \left(S_{i}^{*}\right)$. We note that $t^{\prime}>0$ since the country should make positive tax revenue in equilibrium. Assume to the contrary that the country $j$ sets a tax $t^{*}, t_{i}^{\prime} \leq t^{*}<t_{i}^{\prime \prime}$ with probability $w$. We show that country $i$ can increase its revenue by changing strategy.

We know that there are no "holes" in the strategy set for country $i$. Consider the revenues of the $i$ th country when it sets $\left(t^{*}-\epsilon\right)$ and $\left(t^{*}+\epsilon\right), \epsilon>0$. These are given respectively by 


$$
\alpha\left(t^{*}-\epsilon\right)+\left[1-F_{j}\left(t^{*}-\epsilon\right)\right]\left(t^{*}-\epsilon\right)
$$

And,

$$
\alpha\left(t^{*}+\epsilon\right)+\left[1-F_{j}\left(t^{*}+\epsilon\right)\right]\left(t^{*}+\epsilon\right)
$$

Subtracting (A2) from (A1) we get

$$
-2 \epsilon(1+\alpha)+t^{*}\left[F_{j}\left(t^{*}+\epsilon\right)-F_{j}\left(t^{*}-\epsilon\right)\right]+\epsilon\left[F_{j}\left(t^{*}-\epsilon\right)+F_{j}\left(t^{*}+\epsilon\right)\right]
$$

For small enough $\epsilon$, this is strictly positive for $\alpha=1$ as well as $\alpha=0$. This suggest that country $i$, by shifting some mass to the left of $t^{*}$ from the right of $t^{*}$, can be made strictly better off, contradicting the equilibrium.

Now we consider the case when $t^{*}=t_{i}^{\prime \prime}$ and country $i$ has a mass point at $t_{i}^{\prime \prime}$ equal to $w_{i}$. In this case country $i$ can do better by charging $\left(t_{i}^{\prime \prime}-\epsilon\right)$ with probability $w_{i}$ and charging $t_{i}^{\prime \prime}$ with zero probability.

Step 4. Next, we show that the two sets of strategies $S_{i}^{*}$ and $S_{j}^{*}$ are identical when neither country has a mass point. If country $j$ has a mass point at $t^{\prime \prime}$, then country $i$ will set $t^{\prime \prime}$ with zero density in equilibrium. That is, country $i$ will randomize in the half open interval $\left[t^{\prime}, t^{\prime \prime}\right)$ when country $j$ has a mass point at $t^{\prime \prime}$.

To see this, consider the case of no mass points. Assume to the contrary that (without loss of generality) $S_{i}^{*} \subset S_{j}^{*}$. This implies that an interval exists with country $i$ having no support over the interval, but country $j$ does. Further, from Step 2, this interval where country $i$ has no support is either at the lower or at the upper end. That is, for $t_{j} \in I=S_{j}^{*}-$ $S_{j}^{*} \cap S_{i}^{*}$, either $t_{j}<t_{i}^{\prime}$ or $t_{j}>t_{i}^{\prime \prime}$. If the interval is below $t_{i}^{\prime}$, then firm $j$ is strictly better off by charging $t_{i}^{\prime}$ with probability $F_{j}\left(t_{i}^{\prime}\right)$ and not set taxes below $t_{i}^{\prime}$ with positive density. However, if such an interval exists above $t_{i}^{\prime \prime}$, then firm $j$ is strictly better off charging $t_{i}^{\prime \prime}$ with probability $\left[1-F_{j}\left(t_{i}^{\prime \prime}\right)\right]$ and not setting taxes in this interval. In either case, randomizing over the same set as the rival strictly dominates randomizing over $S_{j}^{*}$.

Assume now that country $j$ has a mass point at $t_{j}^{\prime \prime}$. It is easy to argue that country $i$ is better off setting taxes arbitrary close to $t_{j}^{\prime \prime}$.

Step 5. Now we show that $\sup \left(S_{A}^{*}\right)=1$. To see this, suppose $\sup \left(S_{A}^{*}\right)=t^{\prime \prime}<1$. The revenue for country $\mathrm{A}$ is equal to $\alpha t^{\prime \prime}$ because the other country sets the tax rate below $t^{\prime \prime}$ with probability one. Therefore, country A does better by setting the tax rate equal to 1 .

Now we show that proposed strategies described by (3) and (4) constitutes a mixed strategy Nash equilibrium.

Step 6. If country A (country B) sets a tax rate $t \in\left(\frac{1}{2}, 1\right)$, their expected tax revenue can be represented as

$$
T R_{A 2}=t+t\left[1-F_{B}(t)\right]
$$

Substituting for $F_{B}(t)$ we get

$$
T R_{A 2}=t+t\left[1-\left(2-\frac{1}{t}\right)\right]=1
$$

Similarly, we have

$$
T R_{B 2}=t\left[1-\left(1-\frac{1}{2 t}\right)\right]=\frac{1}{2} .
$$

From (A4) and (A6), it is clear that countries earn equal tax revenues everywhere on the support.

We already observed that country A cannot do better by setting a tax rate below $\frac{1}{2}$. We only need to check whether country $B$ has an incentive to undercut by a margin of $F$ and set a tax rate $t \leq 1-F$. If country $B$ sets the tax rate equal to $1-F$ then its tax revenue is equal to

$$
(1-F)+\frac{1}{2}(1-F)
$$


Note that $(1-F)+\frac{1}{2}(1-F) \leq \frac{1}{2}$ when $F \geq \frac{2}{3}$. If country $B$ sets a tax rate lower than $(1-F)$ then we have $\frac{\partial T R_{B 2}}{\partial t}=\frac{F}{2(t+F)^{2}}>0$. Hence, its tax revenue decreases if the tax rate is reduced.

Proof of Lemma 8. We derive a unique subgame-perfect Nash equilibrium of the game starting at the stage where one country adopts a non-preferential, and the other adopts a preferential taxation regime. We show that the country which adopts a non-preferential taxation regime offers a larger tax rebate during the initial period and attract the investor in period 1 . This is true for all $F>0$.

Without a loss of generality, suppose country A adopts a non-preferential taxation regime and, country $B$ adopts a preferential taxation regime.

Firstly, consider the case when $F \geq \frac{2}{3}$. If country $B$ attracts the investor in period one it earns $F$ in period two. If country $A$ attracts the investor, country $B$ earns $\frac{1}{2}$ in period two. Therefore, the maximum tax subsidy country $B$ is willing to offer in period 1 is equal to $\left(F-\frac{1}{2}\right)$. If the investor invests in country $B$ then it pays $\frac{1}{2}$ over two periods. Country $A$ earns 1 when it attracts the investor in period 1 . Country $A$ earns 0 when it fails to attract the investor in period 1 . Suppose country $A$ offers a tax subsidy equal to 1 in period 1 and, the investor invests in country $A$. The maximum tax payments in period two is equal to 1 , therefore, the expected tax payment by the old investor over two-period is equal to 0 . The investor will invest in country $A$ as long as the expected payment is less than $\frac{1}{2}$. Therefore, country A can offer a tax rebate less than 1 and attract the investor in period one. Therefore, when $F \geq \frac{2}{3}$, the country which adopts a non-preferential regime attracts the investor in period 1.

Second, consider the case when $\mathrm{F}$ takes an intermediate value, i.e., $\Delta \leq F<\frac{2}{3}$. If country B fails to attract the investor in period 1 , its tax revenue in period 2 is equal to $\Phi<F$. If the country attracts the investor in period 1 , its tax revenue in period 2 is equal to $F$. Therefore, the maximum tax rebate country $B$ offers to attract the investor in period 1 is equal to $F-\Phi$. If country $\mathrm{A}$ attracts the investor in period one, its tax revenue in period 2 is equal to $\frac{\Phi}{1-\Phi}$. If country $A$ fails to attract the investor in period 1 , its tax revenue in period 2 is equal to 0 . Therefore, the maximum tax rebate country $A$ offers in period 1 is equal to $\frac{\Phi}{1-\Phi}$. We argue that country $A$ offers a tax rebate of less than $\frac{\Phi}{1-\Phi}$ in period 1 and attracts the investor. Suppose country $A$ offers a tax subsidy equal to $\frac{\Phi}{1-\Phi}$ in period 1. If the investor invests in country $A$ then the combined tax revenue of the two competing countries in period 2 is equal to $\frac{\Phi}{1-\Phi}+\Phi$, where the first term is the tax revenue of country $A$, and the second term is the tax revenue of country $B$. Note that the minimum tax rate country $B$ sets in the mixed strategy Nash equilibrium in period 2 is equal to $\frac{\Phi}{1-\Phi}-F$, which is also equal to the minimum amount the new investor (the investor who enters in period 2) pays as taxes in period 2 . Therefore, the maximum tax payments in period 2 by the investor from period 1 is equal to $\left(\frac{\Phi}{1-\Phi}+\Phi\right)-\left(\frac{\Phi}{1-\Phi}-F\right) \equiv$ $\Phi+F$. Therefore, if country A offers a tax rebate of $\frac{\Phi}{1-\Phi}$ in period 1 , and the investor invests in country $A$ in period 1 then the maximum tax amount the investor pays over two periods is equal to $\Phi+F-\frac{\Phi}{1-\Phi}$. Moreover, the total tax payments over two periods if the investor invests in country $\mathrm{B}$ equals $-(F-\Phi)+F \equiv \Phi$, where the first term is the tax 
rebate in period 1 , and the second term is the tax levied by country $B$ in period 2 . Note that $\Phi+F-\frac{\Phi}{1-\Phi}<\Phi$ because $\frac{\Phi}{1-\Phi}>F$. Therefore, country A offers a tax rebate smaller than $\frac{\Phi}{1-\Phi}$ and attracts the investor in period 1. Because the expected tax revenue of country A in period 2 is equal to $\frac{\Phi}{1-\Phi}$, country A receives a strictly positive tax revenue over two periods.

Third, consider the case when $0<F<\Delta$. As before, the maximum tax rebate country $B$ is willing to offer in period one is equal to $F-\left(\Delta+\Delta^{2}\right) F$. If the investor invests in country $B$, it pays $\left(\Delta+\Delta^{2}\right) F$ over two-period. Country A earns $(1+\Delta) F$ if it attracts the investor in period one. Suppose country $A$ offers tax subsidy of $(1+\Delta) F$ in period one. If the investor invests in country $A$ then its expected payment over two-period is less than $(1+\theta) F-(1+\Delta) F \equiv \Delta^{2} F$. Therefore, country A offers a tax subsidy smaller than $(1+\Delta) F$ in period one and attracts the investor.

Therefore, we observed that for all values of $F$ country $\mathrm{A}$ attracts the investor and earns strictly positive tax revenues over two periods.

\section{Appendix B}

Proof of Lemma 5: We need to show that strategies defined by (7) and (8) constitutes a unique Nash equilibrium. First, we will show that the distribution of taxes over the support are continuous. From (8), we have

$$
\lim _{\epsilon \rightarrow 0} F_{B}(\varnothing+\epsilon)=2-\frac{\emptyset}{(1-\varnothing) \emptyset} \equiv \frac{1-2 \emptyset}{1-\varnothing}
$$

, and

$$
\lim _{\epsilon \rightarrow 0} F_{B}(1-F-\epsilon)=\frac{(1-F+F)(1-\emptyset)-\emptyset}{(1-F+F)(1-\varnothing)} \equiv \frac{1-2 \emptyset}{1-\varnothing} .
$$

From (B1) and (B2) it is clear that the distribution of taxes over the support of country $B$ is continuous. Similarly, we must have $\lim _{\epsilon \rightarrow 0} F_{A}\left(\frac{\varnothing}{1-\varnothing}+\epsilon\right)=\lim _{\epsilon \rightarrow 0} F_{A}\left(\frac{\varnothing}{1-\varnothing}-\epsilon\right)$. From (7) we have

$$
\lim _{\epsilon \rightarrow 0} F_{A}\left(\frac{\varnothing}{1-\varnothing}+\epsilon\right)=2-\frac{\varnothing}{1-\frac{1-2 \emptyset}{1-\varnothing}-F}
$$

And,

$$
\lim _{\epsilon \rightarrow 0} F_{A}\left(\frac{\emptyset}{1-\emptyset}+\epsilon\right)=1-\frac{\emptyset}{1-\frac{1-\not \varnothing}{1-\varnothing}}
$$

If left hand sides of (B3) and (B4) are equal, then right hand sides should be equal as well. Therefore, we have

$$
2-\frac{\varnothing}{1-\frac{1-2 \emptyset}{1-\varnothing}-F}=1-\frac{\varnothing}{1-\frac{1-2 \varnothing}{1-\varnothing}}
$$

Solving (B5) for $\varnothing$ we get

$$
\phi \equiv \frac{1}{2 F}\left(1+3 F-\sqrt{6 F+F^{2}+1}\right) .
$$

From (5) and (B6), it is clear that the distribution of taxes over the support of country A is also continuous. The remaining part of the proof we show in two steps. In step 1 we show 
that competing countries earn an equal amount everywhere on the support. In step 2 we show that a country cannot do better by adopting a different strategy.

Step 1: First, we show that country $A$ earns an equal amount everywhere on the support. Using (8), the tax revenue of country $A$ when it sets a tax rate $t \in\left(\varnothing, \frac{\emptyset}{1-\varnothing}\right)$ can be represented as

$$
t+t\left[1-F_{B}(t)\right] \equiv t+t\left[1-\left(2-\frac{\varnothing}{(1-\emptyset) t}\right)\right] .
$$

After simple manipulation the above equation can be represented as

$$
\frac{\emptyset}{1-\emptyset} \text {. }
$$

Similarly, if country A sets a tax rate $t \in\left(\frac{\varnothing}{1-\varnothing}, 1\right)$, its tax revenue is $t\left[1-F_{B}(t)\right] \equiv$ $t\left[1-\left(2-\frac{\emptyset}{(1-\emptyset) t}\right)\right]$. After simple manipulation we obtain

$$
\frac{\emptyset}{1-\emptyset}
$$

Taking note of the fact that the distribution of taxes of the support of country $B$ is continuous with no probability mass anywhere on the support, we can conclude using (B7) and (B8) that country A obtains an equal tax revenue everywhere on its support.

Similarly, we show that country B obtains equal tax revenues everywhere on its support. When country $B$ sets $t \in\left(\varnothing, \frac{\varnothing}{1-\varnothing}\right)$, its tax revenue is given as

$$
t\left[1-F_{A}(t)\right]=\varnothing .
$$

When country B sets the tax rate $t \in\left(\frac{\emptyset}{1-\emptyset}-F, 1-F\right)$, its tax revenue is

$$
t+t\left[1-F_{A}(t+F)\right]=\varnothing .
$$

From (B9) and (B10), it is clear that country B earns an equal tax revenue everywhere on the support.

Step 2. Now we prove that no country can do strictly better from unilateral deviation. Note that country $B$ does not set taxes such that $1-F<t<\emptyset$. Hence, if country $A$ deviates and sets a tax rate such that $1-F<t<\emptyset$, then it is not undercutting the tax rate of country $B$ with a greater probability but still setting a lower tax rate. Suppose country $A$ deviates and sets a tax rate such that $\frac{\emptyset}{1-\varnothing}-F<t<1-F$. In this scenario, country $A$ is undercutting the tax rate of country $B$ with greater probability. Distribution of taxes of country $\mathrm{B}$ over the range $\left(\frac{\varnothing}{1-\varnothing}-F, 1-F\right)$ will determine the benefits to country $\mathrm{A}$ from such a deviation. The tax revenue of country $A$ is equal to

$$
t+t\left[1-F_{B}(t)\right]=t+\frac{t}{t+F}\left(\frac{\varnothing}{1-\varnothing}\right) .
$$

Differentiating (B11) with respect to $t$ we obtain

$$
1+\left(\frac{\emptyset}{1-\emptyset}\right) \frac{F}{(t+F)^{2}}>0
$$


Therefore, the tax revenue of country $A$ reduces when it reduces the tax rate in the range $\frac{\varnothing}{1-\varnothing}-F<t<1-F$. If country A sets $t=\frac{\varnothing}{1-\varnothing}-F$, it attracts investments from both investors with probability one and earn $2\left(\frac{\varnothing}{1-\varnothing}-F\right)$. But note that

$$
2\left(\frac{\varnothing}{1-\varnothing}-F\right)>\frac{\varnothing}{1-\varnothing} \Rightarrow \frac{\varnothing}{1-\varnothing}>2 F
$$

, which is not true. Therefore, we conclude that country A cannot do better from a unilateral deviation.

Now we show that country $B$ has no incentive to deviate from proposed strategy unilaterally. Following arguments similar to above, it is easy to see that country B cannot do better by setting a tax rate $t$ such that $1-F<t<\emptyset$. We need to check for $t \in\left(\frac{\varnothing}{1-\varnothing}, 1\right)$ and $t<\frac{\varnothing}{1-\varnothing}-F$. From (7), the tax revenue of country $B$ for $t \in\left(\frac{\varnothing}{1-\varnothing}, 1\right)$ is equal to

$$
t\left(\frac{\emptyset-t-F}{t-F}\right)
$$

Differentiating (B14) with respect to $t$ we obtain

$$
-1-\frac{F \varnothing}{(t-F)^{2}}<0
$$

Therefore, country B's tax revenue decreases from increasing the tax rate in the range $\left(\frac{\emptyset}{1-\varnothing}, 1\right)$. The tax revenue of country B when it deviates in the range $\emptyset-F<t<\frac{\varnothing}{1-\varnothing}-F$ is equal to

$$
t+t\left[1-F_{A}(t+F)\right]
$$

Using (7), the tax revenue described in (B16) can be represented as

$$
t+t\left(\frac{\varnothing}{t+F}\right)
$$

Differentiating (B17) with respect to $t$ we obtain $1+\frac{\emptyset F}{(t+F)^{2}}$ which is greater than zero, that is tax revenue is increasing in $t$. From (B16) and (B17), it is clear that the tax revenue of country $B$ is decreasing in its tax rate if the tax rate is greater than $\frac{\emptyset}{1-\varnothing}$, and the tax revenue is increasing in its taxes when it lower than $\frac{\varnothing}{1-\varnothing}-F$. This proves that country $B$ cannot do better by unilaterally deviation. Using the argument in Appendix $C$, we state this equilibrium is unique.

Proof of Lemma 6. Here we show that the proposed strategies constitute a mixed strategy Nash equilibrium. The existence and uniqueness of the equilibrium follow directly from Fisher and Wilson (1995). The sketch of the proof is provided in an online appendix (Appendix C).

First, we show that the distribution of taxes of competing countries are continuous over the support. Distribution of taxes over the support of country $A$ for taxes over the range $[\theta F,(1+\Delta) F]$ and $[(1+\Delta) F,(1+\theta) F]$ is given by (9).

$$
\lim _{\in \rightarrow 0} \mathcal{F}_{A}[(1+\Delta) F+\in]=2-\frac{\theta F}{(1+\Delta) F-F} \equiv 2-\frac{\theta F}{\Delta F}
$$

Substituting $\theta=\Delta(1+\Delta)$ in the above equation we obtain 


$$
\begin{gathered}
\lim _{\in \rightarrow 0} \mathcal{F}_{A}[(1+\Delta) F+\in]=1-\Delta . \\
\lim _{\in \rightarrow 0} \mathcal{F}_{A}[(1+\Delta) F-\in]=1-\frac{\theta F}{(1+\Delta) F} .
\end{gathered}
$$

Substituting $\theta=\Delta(1+\Delta)$ in the above equation we obtain

$$
\lim _{\in \rightarrow 0} \mathcal{F}_{A}[(1+\Delta) F-\in]=1-\Delta .
$$

From (B17) and (B18), we have

$$
\lim _{\epsilon \rightarrow 0} \mathcal{F}_{A}[(1+\Delta) F+\epsilon]=\lim _{\epsilon \rightarrow 0} \mathcal{F}_{A}[(1+\Delta) F-\epsilon] .
$$

Distribution of taxes over the support of country B is given by (10). From (10) we have

$$
\lim _{\in \rightarrow 0} \mathcal{F}_{B}[\theta F+\in]=2-\frac{(1+\Delta) F}{\theta F} .
$$

Substituting $\theta=\Delta^{2}+\Delta$ in the above equation we obtain

$$
\lim _{\in \rightarrow 0} \mathcal{F}_{B}[\theta F+\in]=2-\frac{1}{\Delta}
$$

From (10) we have

$$
\lim _{\epsilon \rightarrow 0} \mathcal{F}_{B}[\theta F-\epsilon]=1-\frac{(1+\Delta) F}{\theta F+F} .
$$

Substituting $\Delta^{2}+\Delta$ for $\theta$ in the above equation we obtain

$$
\lim _{\epsilon \rightarrow 0} \mathcal{F}_{B}[\theta F-\epsilon]=\frac{\Delta^{2}}{1+\Delta+\Delta^{2}} .
$$

From (B20) and (B21), it is clear that the distribution of taxes over the support of country $\mathrm{B}$ is continuous when $2-\frac{1}{\Delta}=\frac{\Delta^{2}}{1+\Delta+\Delta^{2}}$, or, equivalently $\Delta^{3}+\Delta^{2}+\Delta-1=0$. Note that $\Delta$ is the value of $F$ such that $1-F=\emptyset$. Substituting $\frac{1}{2 F}\left(1+3 F-\sqrt{6 F+F^{2}+1}\right)$ for $\phi$ we obtain $F^{3}+F^{2}+F-1=0$. Therefore, we have

$$
\lim _{\epsilon \rightarrow 0} \mathcal{F}_{B}[\theta F+\in]=\lim _{\epsilon \rightarrow 0} \mathcal{F}_{A}[\theta F-\in] .
$$

From (B19) and (B22), it is clear that the distributions of taxes over the support of country $A$ and country $B$ are continuous.

The remaining part of the proof we show in two steps. In step (1), we show that competing countries receive an equal tax revenue everywhere on the support. In step (2), we show that competing countries cannot do better by unilateral deviation from the proposed strategies.

Step (1): Suppose country A sets the tax rate $t_{A 2}$ in the range $((1+\Delta) F,(1+\theta) F)$. The expected tax revenue is equal to $t_{A 2}\left[1-\mathcal{F}_{B}\left(t_{A 2}-F\right)\right]$. Note that in this case $t_{A 2}-$ $F \in(\Delta F, \theta F)$. Using (10), the expected tax revenue of country $\mathrm{A}$ is:

$$
t_{A 2}\left(\frac{(1+\Delta) F}{t_{A 2}-F+F}\right) \equiv(1+\Delta) F .
$$

Similarly, when country A sets $t_{A 2} \in(\theta F,(1+\Delta) F)$, the tax revenue is equal to

$$
t_{A 2}+t_{A 2}\left[1-\left(2-\frac{(1+\Delta) F}{t_{A 2}}\right)\right] \equiv(1+\Delta) F .
$$


From (B23) and (B24), it is clear that country receives an equal tax revenue everywhere on the support. Similarly, suppose country $B$ sets $t_{B 2} \in[\Delta F, \theta F]$, that is $t_{B 2}+F \in$ $[(1+\Delta) F,(1+\theta) F]$. Using (9), the tax revenue of country $B$ is

$$
t_{B 2}+t_{B 2}\left[1-\left(2-\frac{\theta F}{t_{B 2}+F-F}\right)\right] \equiv \theta F
$$

Similarly, if country $B$ sets $t_{B 2} \in[\theta F,(1+\Delta) F]$ then its tax revenue is $t_{B 2}\left[1-\mathcal{F}_{A}\left(t_{B 2}\right)\right]$. Using (9), the tax revenue is represented as

$$
t_{B 2}\left[1-\left(1-\frac{\theta F}{t_{B 2}}\right)\right] \equiv \theta F .
$$

From (B25) and (B26), it is clear that country B earns an equal tax revenue everywhere on the support. Now in step (2), we show that no country can do strictly better from unilateral deviation.

Step (2): First, we show that country A do not find it beneficial to set a tax rate outside the support. Suppose country A sets a tax rate greater than $(1+\theta) F$. Using (10), we can state that the expected tax revenue of country $A$ at the tax rate $t_{A 2}$ is equal to

$$
T R_{A 2}=t_{A 2}\left[1-\mathcal{F}_{B}\left(t_{A 2}-F\right)\right] \equiv \frac{t_{A 2} T R_{A 2}}{t_{A 2}-F}-t_{A 2} .
$$

From the above equation we have

$$
\frac{\partial T R_{A 2}}{\partial t_{A 2}}=-\frac{F \cdot T R_{A 2}}{\left(t_{A 2}-F\right)^{2}}-1<0 .
$$

From (B27), it is clear that country A cannot do better by setting a tax rate higher than $(1+\theta) F$. Now, suppose country $A$ sets a tax rate $t_{A 2}$ which is lower than the infimum of the support. Note that if it sets a tax rate lower than $\Delta F$, then the maximum tax revenue it can obtain is equal to $2 \Delta F$, which is less than equilibrium tax revenues. Hence, we only need to verify that tax revenue of country $\mathrm{A}$ for $t_{A 2}>\Delta F$. From (10), the tax revenue of country $A$ in this case is equal to

$$
T R_{A 2}=t_{A 2}+t_{A 2}\left[1-\mathcal{F}_{B}\left(t_{A 2}\right)\right]=t_{A 2}+t_{A 2}\left[\frac{T R_{A 2}-t_{A 2}}{t_{A 2}}\right] \equiv T R_{A 2} .
$$

From (B27) and (B28), it is clear that country A cannot do better if it sets a tax rate outside the proposed support for the mixed strategy Nash equilibrium. Now, we show that country $B$ cannot set a tax rate outside its support and do strictly better. Suppose country $B$ deviates and sets a tax rate which is lower than the infimum of the support. If it sets $t_{B 2} \equiv(\theta F-F)$ or less, it can attract both investors with probability one, but it earns negative tax revenues. Thus, we concentrate on the range of taxes at which country $B$ attracts the new investor with probability one and attracts the investor residing in country A with a positive probability, that is $t_{B 2} \in(0, \Delta F)$. In this case, the tax revenue of country B equals $T R_{B 2} \equiv t_{B 2}+t_{B 2}\left[1-\mathcal{F}_{A}\left(t_{B 2}+F\right)\right]$. Using (9), we can represent the same as

$$
T R_{B 2}=t_{B 2}+t_{B 2}\left[1-\left(2-\frac{T R_{B 2}}{t_{B 2}+F-F}\right)\right] \equiv T R_{B 2} .
$$

Now, if country B sets a tax rate above the supremum of the support of country $A$, it gets tax revenues equal to 0 . Suppose country $\mathrm{B}$ sets a tax rate $t_{B 2}$ which is greater than the supremum of the support of country $B$ but less than the supremum of country $A$, that is $t_{B 2} \in((1+\Delta) F,(1+\theta) F)$. The tax revenue of country $B$ is equal to $T R_{B 2} \equiv$ $t_{B 2}\left[1-\mathcal{F}_{B}\left(t_{B 2}\right)\right]$. Using (9), we can represent the tax revenue $T R_{B 2}$ as: 


$$
T R_{B 2}=t_{B 2}\left(\frac{T R_{B 2}}{t_{B 2}}\right) \equiv T R_{B 2}
$$

From (B29) and (B30), it is clear that country B cannot do strictly better by setting a tax rate outside its support for proposed mixed strategy Nash equilibrium.

\section{Appendix C (Should be online)}

Following Fisher and Wilson (1995), we prove the uniqueness of mixed strategy Nash equilibrium. Let $G_{i}(t)$ be the decumulative distribution function of the tax rates charged by country $i$, that is $G_{i}(t)=1-F_{i}(t)$ where $F_{i}(t)$ is the distribution function. The function $G_{i}(t)$ may not be continuous. Let $q_{i}(t)$ denote the probability mass of $G_{i}(t)$ at the tax rate $t$. Without a loss of generality, we assume that country $A$ attracts the investor in period one.

$G_{i}(t)$ is the probability that country $i$ sets a tax rate greater than or equal to $t$. Then

$$
T_{A}\left(t, G_{B}\right)=\left[G_{B}(t-F)-\frac{q_{B}(t-F)}{2}\right]+\left[G_{B}(t)-\frac{q_{B}(t)}{2}\right]
$$

Is the expected tax revenue of country A from setting the tax rate equal to $t . G_{B}(t-F)$ is the probability that country $\mathrm{B}$ sets the tax rate greater than $(t-F)$. The $q_{B}(t-F)$ reflects the assumption that country $A$ keeps its domestic investor with probability $1 / 2$ when both sets the same tax rate. Similarly, $G_{B}(t)$ is the probability that country B sets the tax rate greater than $t$ so that country $A$ attracts the new investor in period two. The term $\frac{q_{B}(t)}{2}$ reflect the assumption that country $A$ attracts the new investor with probability $1 / 2$ when two countries set an equal tax rate. Similarly,

$$
T_{B}\left(t, G_{A}\right)=\left[G_{A}(t+F)-\frac{q_{A}(t+F)}{2}\right]+\left[G_{A}(t)-\frac{q_{A}(t)}{2}\right]
$$

Is the expected tax revenue of country $B$ from setting the tax rate equal to $t$. Although the expected tax revenue of country $i$ may not be continuous in $t$,

$$
\lim _{\delta \rightarrow 0} T_{A}\left(t-\delta, G_{B}\right) \geq T_{A}\left(t, G_{B}\right) \geq \lim _{\delta \rightarrow 0} T_{A}\left(t+\delta, G_{B}\right)
$$

for $t \in[0,1]$ because undercutting firm $j$ causes a discrete increase in country $A$ 's expected tax revenues if country $B$ sets $t$ or $t-F$ with strictly positive probability. The same is true for country $\mathrm{B}$ if country $\mathrm{A}$ sets $t$ or $t+F$ with strictly positive probability. Let $\mathcal{V}_{i}=$ $\sup _{t \geq 0} T_{i}\left(t, G_{j}\right)$ be the highest expected tax revenues of country $i$, given that country $j$ follows the strategy $G_{j}$. Then pair of strategies $\left(G_{A}, G_{B}\right)$ is an equilibrium if

$$
\int T_{A}\left(t, G_{B}\right) d G_{B}=\mathcal{V}_{A}
$$

and,

$$
\int T_{B}\left(t, G_{A}\right) d G_{A}=\mathcal{V}_{B} .
$$

Lemma 1C. If $F>0$, then $\mathcal{V}_{A}>0$ and $\mathcal{V}_{B}>0$.

Note that $F>0$ inures positive revenues for country A. Therefore, the support of taxes chosen by country A must be bounded away from zero.

Lemma 2C. $q_{A}(t)>0$ implies $t=1$ and $q_{B}(t)=0$.

Proof. Lemma 2 implies that country A can have a probability mass at 1 , and country $B$ cannot have a probability mass anywhere on the support. Suppose country $A$ has a 
probability mass of $w>0$ at $t<1$. Then there is a $\delta>0$ such that $G_{B}(t-F+\delta)=$ $G_{B}(t-F)$ and $G_{B}(t+\delta)=G_{B}(t)$. Because each country earns positive revenues $G_{B}(t-F)>0$ and $G_{B}(t)>0$. Then from (C1), we can observe that the expected revenues of country $A$ is greater at $(t+\delta)$ compared to $t$. Note that when country $A$ has a mass point at $t>0$, country $\mathrm{B}$ cannot have a mass point because it can reduce its tax rate by a small margin and increase tax revenues. If country $\mathrm{A}$ has a mass point at $t=1$, then it cannot increase its tax rate. Therefore, we conclude that country $A$ can only have a probability mass at $t=1$.

It follows from the above discussion that country $\mathrm{B}$ cannot have a mass point at $t \neq 1$. Now we will show that country $\mathrm{B}$ cannot have a mass point at $t=1$. It is not beneficial for country $B$ to have a mass point at 1 if country $A$ also has a mass point at 1 . If country $A$ has no mass point then country $B$ is not undercutting the tax rate of country $A$ with a positive probability. Therefore, country $B$ can reduce its tax rate and do better. Therefore, we conclude that country B cannot have a mass point anywhere on its support. The proof is complete.

Define $m_{i}=\sup \left\{t: G_{i}(t)=1\right\}$ and $M_{i}=\inf \left\{t: G_{i}(t)=0\right\}$. These are the lower and upper bounds of the support of the strategy $G_{i}$.

Lemma 3C. (a) $G_{B}\left(M_{A}-F\right)>0$ and $G_{A}\left(M_{B}-F\right)>0$. (b) $G_{A}\left(M_{B}+F\right)=0$ and $G_{B}\left(M_{A}\right)=$ 0 ; (c) $M_{A}-F \leq M_{B} \leq 1$, and $M_{B} \leq M_{A} \leq 1$; and (d) $m_{A} \leq m_{B}+F$ and $m_{B} \leq m_{A}$.

Proof. (a) Suppose $G_{i}\left(M_{j}-F\right)=0$. Then the expected revenues for $t$ near $M_{j}$ is also zero. Contradicting Lemma 1.

(b) For $t>\left(M_{B}+F\right)$, the expected revenues of country $\mathrm{A}$ is zero because it loses its domestic investor and the new investor with probability one. Using a similar argument, we can show that $G_{B}\left(M_{A}\right)=0$.

(c) We know that $G_{B}\left(M_{A}-F\right)>0$, which implies $M_{A}-F \leq M_{B} \leq 1$. To see the second inequality, suppose to the contrary that $M_{A}<M_{B}$. The expected revenues of country $\mathrm{B}$ near $M_{B}$ is equal to zero. This contradicts Lemma 1.

(d) Suppose to the contrary that $m_{A}>m_{B}+F$. This implies $m_{B}<m_{A}-F$. Country B attracts both investors with probability one for any tax rate below $m_{A}-F$. Therefore, tax revenues of country $B$ is increasing in the tax rate below $m_{A}-F$. Therefore, it will not set a tax rate below $m_{A}-F$. To prove the second inequality, suppose to the contrary that $m_{B}>m_{A}$. For any tax rate below $m_{B}$, tax revenues of country $A$ is increasing in $t$. Therefore, country A does not set a tax rate below $m_{B}$.

Part (a) states that country B also sets taxes such that it is not undercutting country A's tax rate with probability one. Part (b) states that country $A$ does not set a tax rate so high that it loses its domestic investor with probability one. Moreover, country B does not set a tax rate greater than the supremum of the support of country $A$.

Lemma 4C. $M_{i} \leq 2 F$ for $i=A, B$.

Proof. Suppose country $i$ sets $M_{i}$ then it does not attract the new investor. If it sets $M_{i}-F$ then it also attracts the new investor. Therefore, it makes sense to set $M_{i}$ only if $M_{i} \geq$ $2\left(M_{i}-F\right) \rightarrow . M_{i} \leq 2 F$. 
Using the assumption that $m_{i}<M_{i}-t$, we now establish a lower bound for $M_{i}$.

Lemma 5C. If $m_{i}<M_{i}-F$, then $M_{i}>2 F$

Proof. We establish the lemma in a series of steps. Let $\Pi_{A}^{o}\left(t, G_{B}\right)=t G_{B}(t-F)$ be firm A's expected revenues from its domestic capital (investments from period one), and $\Pi_{A}^{n}\left(t, G_{B}\right)=t G_{B}(t)$ be expected tax revenues from new investments. Similarly, $\Pi_{B}^{o}\left(t, G_{A}\right)=t G_{A}(t+F)$ be firm B's expected revenue from old investments, $\Pi_{B}^{n}\left(t, G_{A}\right)=$ $t G_{A}(t)$ be its revenues from the new investor.

Step 1. Suppose $t^{\prime} \leq t^{\prime \prime} \leq 1-F$. Then $\Pi_{A}^{o}\left(t^{\prime \prime}+F, G_{B}\right) \geq \Pi_{A}^{o}\left(t^{\prime}+F, G_{B}\right)>0$ implies $\Pi_{A}^{n}\left(t^{\prime \prime}, G_{B}\right)>\Pi_{A}^{n}\left(t^{\prime}, G_{B}\right)$. Similarly, $\quad \Pi_{B}^{o}\left(t^{\prime \prime}+F, G_{A}\right) \geq \Pi_{B}^{o}\left(t^{\prime}+F, G_{A}\right)>0 \quad$ implies $\Pi_{B}^{n}\left(t^{\prime \prime}, G_{A}\right)>\Pi_{B}^{n}\left(t^{\prime}, G_{A}\right)$.

Proof. Suppose $\Pi_{A}^{o}\left(t^{\prime \prime}+F, G_{B}\right) \geq \Pi_{A}^{o}\left(t^{\prime}+F, G_{B}\right)>0$. Then $G_{B}\left(t^{\prime \prime}\right)\left(t^{\prime \prime}+F\right) \geq$ $G_{B}\left(t^{\prime}\right)\left(t^{\prime}+F\right)>0$. Therefore, $t^{\prime \prime} G_{B}\left(t^{\prime \prime}\right)+F G_{B}\left(t^{\prime \prime}\right) \geq t^{\prime} G_{B}\left(t^{\prime}\right)+F G_{B}\left(t^{\prime}\right)$. Note that $F G_{B}\left(t^{\prime \prime}\right) \leq F G_{B}\left(t^{\prime}\right)$ because $t^{\prime \prime} \geq t^{\prime}$ implies $G_{B}\left(t^{\prime \prime}\right) \leq G_{B}\left(t^{\prime}\right)$. Therefore, we have $t^{\prime \prime} G_{B}\left(t^{\prime \prime}\right)>t^{\prime} G_{B}\left(t^{\prime}\right)$. The last inequality can be represented as $\Pi_{A}^{n}\left(t^{\prime \prime}, G_{B}\right)>\Pi_{A}^{n}\left(t^{\prime}, G_{B}\right)$. Similarly, we can show that $\Pi_{B}^{o}\left(t^{\prime \prime}+F, G_{A}\right) \geq \Pi_{B}^{o}\left(t^{\prime}+F, G_{A}\right)>0$ implies $\Pi_{B}^{n}\left(t^{\prime \prime}, G_{A}\right)>$ $\Pi_{B}^{n}\left(t^{\prime}, G_{A}\right)$.

Step 2. If $m_{i}+F<M_{i}$, then $m_{B}+F<M_{A}-F \leq M_{B}$ and $m_{A}+F<M_{B} \leq M_{A}$.

Proof. First, we prove it for $i=A$. As before, we define $\Pi_{i}^{o}\left(t, G_{j}\right)$ and $\Pi_{i}^{n}\left(t, G_{j}\right)$ as equilibrium tax revenues from old investments (investments from period one) and new investments, respectively. Therefore, $\Pi_{i}\left(t, G_{j}\right)=\Pi_{i}^{o}\left(t, G_{j}\right)+\Pi_{i}^{n}\left(t, G_{j}\right)$. Since equilibrium tax revenues is strictly positive, it follows that

$$
\Pi_{A}\left(M_{A}, G_{B}\right)-\Pi_{A}\left(m_{A}+F, G_{B}\right) \geq 0 .
$$

Country $A$ and country $B$ are competing over investments from period one (located in country A) and the new investor who is located outside of two countries. Therefore, we have

$$
M_{A} G_{B}\left(M_{A}-F\right)+M_{A} G_{B}\left(M_{A}\right)-\left(m_{A}+F\right) G_{B}\left(m_{A}\right)-\left(m_{A}+F\right) G_{B}\left(m_{A}+F\right) \geq 0 .
$$

Lemma $3 C(\mathrm{~b})$ implies that $G_{B}\left(M_{A}\right)=0$, since in this case country B attracts the new investor with probability zero. Therefore, we have

$$
M_{A} G_{B}\left(M_{A}-F\right)-\left(m_{A}+F\right) G_{B}\left(m_{A}\right)-\left(m_{A}+F\right) G_{B}\left(m_{A}+F\right) \geq 0 .
$$

The above inequality implies

$$
M_{A} G_{B}\left(M_{A}-F\right)-\left(m_{A}+F\right) G_{B}\left(m_{A}\right) \geq 0 .
$$

The above inequality can be represented as

$$
\Pi_{A}^{o}\left(M_{A}, G_{B}\right)-\Pi_{A}^{o}\left(m_{A}+F, G_{B}\right) \geq 0 .
$$

Note that $m_{A}+F \leq M_{A} \leq 1$. Therefore, using step (1) we can state that

$$
\Pi_{A}^{n}\left(M_{A}-F, G_{B}\right)-\Pi_{A}^{n}\left(m_{A}, G_{B}\right) \geq 0 .
$$

Therefore, we have

$$
0 \geq \Pi_{A}\left(M_{A}-F, G_{B}\right)-\Pi_{A}\left(m_{A}, G_{B}\right) \geq \Pi_{A}^{o}\left(M_{A}-F, G_{B}\right)-\Pi_{A}^{o}\left(m_{A}, G_{B}\right)
$$


or,

$$
\left(\mathrm{M}_{\mathrm{A}}-\mathrm{F}\right) G_{B}\left(M_{A}-2 F\right)-m_{A} G_{B}\left(m_{A}-F\right) \leq 0 .
$$

Because $\mathrm{M}_{\mathrm{A}}-\mathrm{F}>m_{A}$, we have $G_{B}\left(M_{A}-2 F\right)<1$. Hence, $m_{B}<M_{A}-2 F$, or $m_{B}+F<$ $M_{A}-F$. Lemma 3C (c) implies that $M_{A}-F \leq M_{B}$. Therefore, we have the desired result

$$
m_{B}+F<M_{A}-F \leq M_{B} .
$$

Similarly, we can show that $m_{A}+F<M_{B} \leq M_{A}$. The proof is complete.

Step 3. If $m_{i}+F<M_{i}$ then $G_{A}\left(M_{B}\right) \leq G_{A}\left(m_{B}+2 F\right)$ and $G_{B}\left(M_{A}-F\right) \leq G_{B}\left(m_{A}+F\right)$.

Proof. First, we prove it for $i=A$. Note that if $M_{B} \geq m_{B}+2 F$ then the results follow immediately. So, let $t \in\left(M_{B}-F, m_{B}+F\right)$. Therefore, following inequality is true

$$
\Pi_{A}\left(t, G_{B}\right)-\Pi_{A}\left(m_{A}, G_{B}\right) \leq 0 .
$$

As before $\Pi_{i}^{o}$ and $\Pi_{i}^{n}$ denote payoffs from old and new investor, respectively. Therefore, we have

$$
\begin{aligned}
\Pi_{A}^{o}\left(t, G_{B}\right)-\Pi_{A}^{o}\left(m_{A}, G_{B}\right)+\Pi_{A}^{n}\left(t, G_{B}\right)-\Pi_{A}^{n}\left(m_{A}, G_{B}\right) & \leq 0 . \\
t G_{B}(t-F)-m_{A} G_{B}\left(m_{A}-F\right)+\Pi_{A}^{n}\left(t, G_{B}\right)-\Pi_{A}^{n}\left(m_{A}, G_{B}\right) & \leq 0 .
\end{aligned}
$$

Note that $t G_{B}(t-F)-m_{A} G_{B}\left(m_{A}-F\right)>0$. Therefore, we have

$$
\begin{gathered}
\Pi_{A}^{n}\left(t, G_{B}\right)-\Pi_{A}^{n}\left(m_{A}, G_{B}\right)<t G_{B}(t-F)-m_{A} G_{B}\left(m_{A}-F\right) \\
+\Pi_{A}^{n}\left(t, G_{B}\right)-\Pi_{A}^{n}\left(m_{A}, G_{B}\right) \leq 0
\end{gathered}
$$

Given the above inequality, we have

$$
\begin{aligned}
& \Pi_{A}\left(t+F, G_{B}\right)-\Pi_{A}\left(m_{A}+F, G_{B}\right) \\
=\left[\Pi_{A}^{0}\left(t+F, G_{B}\right)-\right. & \left.\Pi_{A}^{0}\left(m_{A}+F, G_{B}\right)\right]+\left[\Pi_{A}^{n}\left(t+F, G_{B}\right)-\Pi_{A}^{n}\left(m_{A}+F, G_{B}\right)\right] \\
< & \Pi_{A}^{n}\left(t+F, G_{B}\right)-\Pi_{A}^{n}\left(m_{A}+F, G_{B}\right) \\
= & (t+F) G_{B}(t+F)-\left(m_{A}+F\right) G_{B}\left(m_{A}+F\right) .
\end{aligned}
$$

Note that $t+F>M_{B}$. Therefore, $G_{B}(t+F)=0$. Therefore, we have

$$
\Pi_{A}\left(t+F, G_{B}\right)<\Pi_{A}\left(m_{A}+F, G_{B}\right) .
$$

Hence, it is not optimal to set a tax rate $t \in\left(M_{B}-F, m_{B}+F\right)$. Therefore, we have $G_{A}\left(m_{B}+F\right) \geq G_{A}\left(M_{B}-F\right)$. Therefore, we have $G_{A}\left(m_{B}+2 F\right) \geq G_{A}\left(M_{B}\right)$. Similarly, we can show that $G_{B}\left(M_{A}-F\right) \leq G_{B}\left(m_{A}+F\right)$.

Step 4. If $m_{i}+F<M_{i}$, then $M_{i} \geq \min \left\{1, m_{i}+2 F\right\}$.

Proof. First, we prove it for $i=A$. The proof is immediate if $M_{A} \geq m_{A}+2 F$. Let us consider a tax rate $t \in\left(M_{A}, m_{A}+2 F\right)$. From Lemma (3C), we know that $G_{B}\left(M_{A}\right)=0$. Therefore, it follows that

$$
\Pi_{A}\left(M_{A}, G_{B}\right) \geq \Pi_{A}\left(t, G_{B}\right)
$$

Therefore, 


$$
M_{A} G_{B}\left(M_{A}-F\right) \geq t G_{B}(t-F) .
$$

Note that $G_{B}\left(M_{A}-F\right) \leq G_{B}\left(m_{A}+F\right) \leq G_{B}(t-F)$, where the last inequality is true because $t<m_{A}+2 F$, which implies $t-F<m_{A}+F$. Therefore, it must be the case that $M_{A}=1$ so that $M_{A}<t<m_{A}+2 F$ does not exist.

Similarly, we can show that if $m_{B}+F<M_{B}$, then $M_{B} \geq \min \left\{1, m_{B}+2 F\right\}$.

Step 5. If $m_{i}+F<M_{i}$, then $M_{A}=M_{B}=1$.

Proof. If $m_{i}+F<M_{i}$, then step (2) implies that $m_{j}+F<M_{j}$. Lemma (4) along with step (4) implies that $M_{A}=M_{B}=1$.

Step 6. If $m_{i}+F<M_{i}$, then $M_{i} \geq 2 F$.

Proof. As before, firstly, we prove the result for $i=A$. Note that

$$
0 \leq \Pi_{A}\left(M_{A}, G_{B}\right)-\Pi_{A}\left(m_{A}+F, G_{B}\right) .
$$

The total tax revenues of country $A$ includes revenues from investments in period one and the new investor. Therefore, we have

$$
\left\{\begin{array}{c}
{\left[M_{A} G_{B}\left(M_{A}-F\right)-\left(m_{A}+F\right) G_{B}\left(m_{A}\right)\right]} \\
+\left[M_{A} G_{B}\left(M_{A}\right)-\left(m_{A}+F\right) G_{B}\left(m_{A}+F\right)\right]
\end{array}\right\} \geq 0
$$

From Lemma 3 we know that $G_{B}\left(M_{A}\right)=0$. Therefore, we have

$$
M_{A} G_{B}\left(M_{A}-F\right)-\left(m_{A}+F\right) G_{B}\left(m_{A}\right)-\left(m_{A}+F\right) G_{B}\left(m_{A}+F\right) \geq 0 .
$$

We know $G_{B}\left(m_{A}\right) \geq G_{B}\left(M_{A}-F\right)$. Moreover, from step (2) and step (5), we can conclude that $G_{B}\left(m_{A}+F\right) \geq G_{B}\left(M_{A}-F\right)$. Substituting $G_{B}\left(M_{A}-F\right)$ for $G_{B}\left(m_{A}\right)$ and $G_{B}\left(m_{A}+F\right)$ we obtain

$$
G_{B}\left(M_{A}-F\right)\left[M_{A}-2\left(m_{A}+F\right)\right] \geq 0 .
$$

Therefore, we have $M_{A}-2\left(m_{A}+F\right) \geq 0$. Lemma (1) states that $m_{A}>0$ because the equilibrium payoffs are strictly positive. Therefore, we have $M_{A}>2 F$. Similarly, we can show that $M_{B} \geq 2 F$. This completes the proof of Lemma (5).

Lemma 6C. $M_{i}=\min \left\{m_{i}+F, 1\right\}$.

Proof. First, we will prove the result for $i=A$. Since $m_{A} \geq M_{A}-F$, Lemma 3C(c) implies that $M_{A} \leq \min \left\{m_{A}+F, 1\right\}$. Suppose the strict inequality holds $M_{A}<\min \left\{m_{A}+F, 1\right\}$. Choose $t \in\left(M_{A}-F, \min \left\{m_{A}, 1-F\right\}\right)$. Country $\mathrm{B}$ earns higher revenues at $t$ than at any tax rate in the interval $\left(M_{A}-F, t\right)$ because it attracts the new investor with probability 1 and it does not attract the old investor at any tax rate in this interval. Therefore, country $B$ does not set a tax rate in the range $\left(M_{A}-F, \min \left\{m_{A}, 1-F\right\}\right)$. Then country $\mathrm{A}$ earns greater tax revenues at $m_{A}+F$ then $M_{A}$ because in both cases country A loses the new investor with probability one and retains the new investor with probability one. This contradicts the definition of $M_{A}$. Therefore, we have $M_{A}=\min \left\{m_{A}+F, 1\right\}$. Similarly, we can show that $M_{B}=\min \left\{m_{B}+F, 1\right\}$. The proof is complete. 
